\title{
$\beta$-Secretase BACE1 Is Required for Normal Cochlear Function
}

\author{
Marlen Dierich, ${ }^{1}$ SStephanie Hartmann, ${ }^{2}$ Nadine Dietrich, ${ }^{3}$ Philip Moeser, ${ }^{2}$ Franziska Brede, ${ }^{2}$ Lejo Johnson Chacko, ${ }^{4}$ \\ Konstantin Tziridis, ${ }^{5}$ Achim Schilling, ${ }^{5}$ Patrick Krauss, ${ }^{5}$ Sabine Hessler, ${ }^{2}{ }^{-}$Sandra Karch, ${ }^{2}$ Anneliese Schrott-Fischer, ${ }^{4}$ \\ Michael Blumer, ${ }^{6}{ }^{\circledR}$ Carmen Birchmeier, ${ }^{7}$ Dominik Oliver, ${ }^{1,8,9}$ Tobias Moser, ${ }^{3}$ Holger Schulze, ${ }^{5}$ Christian Alzheimer, ${ }^{2 *}$ \\ (1) Michael G. Leitner, ${ }^{1,10 *}$ and ${ }^{-T}$ Tobias Huth ${ }^{2 *}$ \\ ${ }^{1}$ Institute of Physiology and Pathophysiology, Department of Neurophysiology, Philipps-University Marburg, 35037 Marburg, Germany, ${ }^{2}$ Institut für \\ Physiologie und Pathophysiologie, Friedrich-Alexander-Universität Erlangen-Nürnberg, 91054 Erlangen, Germany, ${ }^{3}$ Institute for Auditory Neuroscience \\ and InnerEarLab, University Medical Center Göttingen, Göttingen, Germany, ${ }^{4}$ Department of Otorhinolaryngology, Medical University of Innsbruck, 6020 \\ Innsbruck, Austria, ${ }^{5}$ Experimental Otolaryngology, Friedrich-Alexander-Universität Erlangen-Nürnberg, 91054 Erlangen, Germany, ${ }^{6}$ Division Clinical and \\ Functional Anatomy, Medical University of Innsbruck, 6020 Innsbruck, Austria, ${ }^{7}$ Developmental Biology/Signal Transduction, Max-Delbrück-Center for \\ Molecular Medicine, 13125 Berlin, Germany, ${ }^{8 D F G}$ Research Training Group, Membrane Plasticity in Tissue Development and Remodeling, GRK 2213, \\ Philipps University, Germany, ${ }^{9}$ Center for Mind, Brain and Behavior (CMBB), Universities of Marburg and Giessen, Germany, and ${ }^{10}$ Institute of Physiology, \\ Department of Physiology and Medical Physics, Medical University of Innsbruck, 6020 Innsbruck, Austria
}

Cleavage of amyloid precursor protein (APP) by $\beta$-secretase BACE1 initiates the production and accumulation of neurotoxic amyloid- $\beta$ peptides, which is widely considered an essential pathogenic mechanism in Alzheimer's disease (AD). Here, we report that BACE1 is essential for normal auditory function. Compared with wild-type littermates, BACE $1^{-1-}$ mice of either sex exhibit significant hearing deficits, as indicated by increased thresholds and reduced amplitudes in auditory brainstem responses (ABRs) and decreased distortion product otoacoustic emissions (DPOAEs). Immunohistochemistry revealed aberrant synaptic organization in the cochlea and hypomyelination of auditory nerve fibers as predominant neuropathological substrates of hearing loss in BACE1 ${ }^{-l-}$ mice. In particular, we found that fibers of spiral ganglion neurons (SGN) close to the organ of Corti are disorganized and abnormally swollen. BACE1 deficiency also engenders organization defects in the postsynaptic compartment of SGN fibers with ectopic overexpression of PSD95 far outside the synaptic region. During postnatal development, auditory fiber myelination in $\mathrm{BACE} 1^{-1-}$ mice lags behind dramatically and remains incomplete into adulthood. We relate the marked hypomyelination to the impaired processing of Neuregulin-1 when BACE1 is absent. To determine whether the cochlea of adult wild-type mice is susceptible to AD treatment-like suppression of BACE1, we administered the established BACE1 inhibitor NB-360 for 6 weeks. The drug suppressed BACE1 activity in the brain, but did not impair hearing performance and, upon neuropathological examination, did not produce the characteristic cochlear abnormalities of BACE1 ${ }^{-1-}$ mice. Together, these data strongly suggest that the hearing loss of BACE1 knock-out mice represents a developmental phenotype.

Key words: Alzheimer's disease; auditory function; BACE1; BACE1 inhibitor NB-360; BACE1 knock-out mice; Neuregulin-1

\section{Significance Statement}

Given its crucial role in the pathogenesis of Alzheimer's disease (AD), BACE1 is a prime pharmacological target for AD prevention and therapy. However, the safe and long-term administration of BACE1-inhibitors as envisioned in AD requires a comprehensive understanding of the various physiological functions of BACE1. Here, we report that BACE1 is essential for the processing of auditory signals in the inner ear, as BACE1-deficient mice exhibit significant hearing loss. We relate this deficit to impaired myelination and aberrant synapse formation in the cochlea, which manifest during postnatal development. By contrast, prolonged pharmacological suppression of BACE1 activity in adult wild-type mice did not reproduce the hearing deficit or the cochlear abnormalities of BACE1 null mice.

\section{Introduction}

The amyloid precursor protein (APP), a large type I membrane protein, can be processed along two major pathways, involving sequential cleavage either at the $\alpha$ - and $\gamma$-sites or at the $\beta$ - and $\gamma$-sites of the protein. The latter pathway is initiated by the $\beta$-site APP-cleaving enzyme 1 (BACE1) and leads to the production of potentially neurotoxic amyloid $\beta$-peptides $(A \beta)$. Since its first 
identification in 1999, BACE1 has garnered ever-increasing attention, reflecting its pivotal role in the amyloidogenic pathway that has been closely linked to the pathogenesis of Alzheimer's disease (AD) (Vassar et al., 1999; Yan et al., 1999). Inhibition of BACE1 has therefore emerged as a prime therapeutic strategy to reduce the load of $A \beta$ in the brain (Cole and Vassar, 2007). Quite obviously, however, producing neurotoxic substances cannot be the main function of BACE1. In fact, BACE1 turned out to be important for the proteolytic processing of a plethora of proteins other than APP (Kuhn et al., 2012; Zhou et al., 2012). BACE1 knock-out mice have been-and still are-instrumental to decipher the numerous roles of BACE1 for the proper function of many tissues and organ systems. In general, BACE1-deficient mice show increased mortality after birth and decreased body weight as they mature (Dominguez et al., 2005). With respect to the PNS and CNS, BACE1 ${ }^{-1-}$ mice display a complex phenotype, which includes, at the behavioral level, increased locomotion and ataxia, spontaneous seizures, schizophrenia-like features and decreased thermal pain thresholds, and, at the network and cellular level, neuronal hyperexcitability, aberrant synaptic transmission, axon guidance defects and impaired axonal myelination (Kandalepas and Vassar, 2014; Weber et al., 2017). Importantly, BACE1 levels are high during neuronal development and, with few exceptions, decline with maturation (Willem et al., 2006). Thus, the phenotypes resulting from germline Bace1 deletion might be, at least in part, attributable to the absence of BACE1 during critical developmental periods. An important implication of this notion for the pharmacological prevention and treatment of AD may be that the administration of BACE1 inhibitors in aged patients should not entail major side effects.

Here, we investigated whether BACE1 is required for normal auditory function. Our study was prompted by the finding that Neuregulin-1, a functionally important substrate of BACE1, is expressed in the cochlea (Morley, 1998), and by our previous finding that BACE1 interacts with KCNQ1 and KCNQ4 (Agsten et al., 2015; Hessler et al., 2015), two voltage-dependent $\mathrm{K}^{+}$channels which are essential for normal hearing (Jentsch, 2000; Maljevic et al., 2010). We found that BACE1 ${ }^{-1-}$ mice exhibit significant hearing loss and attribute the phenotype to aberrant synaptic organization in the cochlea and hypomyelination of auditory nerve fibers. We relate the hearing deficits and their neuropathological underpinnings primarily to the lack of BACE1 activity during auditory development, since, in wild-type mice, prolonged pharmacological suppression of BACE1 activity with the established inhibitor NB-360 did not engender hearing deficits or morphological changes.

We thank Dr. Ulf Neumann and Dr. Derya R. Shimshek, Novartis Institutes of BioMedical Research (NIBR), Neuroscience, Basel, for kind support and providing BACE inhibitor NB-360-containing food pellets. We are grateful to Iwona Izydorczyk for technical assistance. We also thank Dr. C. Vogl (Institute for Auditory Neuroscience, Göttingen) for insightful discussions and very helpful comments during development and progression of the project. Furthermore, we thank Dr. M. Schäfer (Institut für Anatomie und Zellbiologie, Marburg) for the great help with establishing research techniques. This work was funded by Research Grants of the University Medical Center Giessen und Marburg (UKGM 17/2013; UKGM 13/2016 to M.G.L.), by the German Research Foundation (DFG Priority Program 1608: "Ultrafast and temporally precise information processing: Normal and dysfunctional hearing", [LE 3600/1-1 to M.G.L.]), and by Tiroler Wissenschaftsförderung (TWF GZ UNI-0404/2381 to M.G.L.). T.M. acknowledges funding from the Collaborative Research Center 889, project A02. This work was supported by the Studienstiftung des deutschen Volkes to S. Hartmann and S.K.

The authors declare no competing financial interests. S. Hartmann became an employee of Novartis Pharma $G \mathrm{mbH}$ only after completion of her experimental contribution.

*C.A., M.G.L., and T. H. contributed equally to this work and are all senior authors.

S. Hartmans's present address: Novartis Pharma GmbH, Roonstr. 25, 90429 Nürnberg, Germany.

Correspondence should be addressed to Michael G. Leitner at Michael.Leitner@i-med.ac.at or Tobias Huth at Tobias.Huth@fau.de.

https://doi.org/10.1523/JNEUROSCI.0028-19.2019

Copyright $@ 2019$ the authors

\section{Materials and Methods}

Animals. BACE1 $1^{\text {tm1Psa }}\left(\mathrm{BACE}^{-1-}\right)$ mice were generated by insertion of a neomycin expression cassette from pMC1neopA into exon 1 of the $B A C E 1$ gene, which introduces a premature translational stop codon into the open reading frame (Dominguez et al., 2005). This strain was crossed back on the C57BL/6J background for $>10$ generations. NRG1- $\beta$ mice carry a premature stop in exon 8 of Neuregulin-1 (Nrg1) which encodes the $\beta$ variant of the EGF domain, whereas the $\alpha$ variant remains intact. The type III $\beta$ NRG1 variant is essential for Schwann cell development (Li, 2003). Homozygous Nrg1- $\beta$ mice die during embryogenesis and, therefore, only heterozygous animals were used for experiments. Mice had ad libitum access to food and water. Housing, feeding, breeding, and handling of the mice were according to federal/institutional guidelines with the approval of the local government. Mice of each sex were used for experiments.

BACE1 inhibitor treatment. Ten C57BL/6N mice (four weeks old) of either sex were fed with food pellets containing the preclinical BACE1 inhibitor NB-360 (Novartis, Neumann et al., 2015) at a concentration of $0.3 \mathrm{~g} / \mathrm{kg}$ for 6 weeks. A cohort of $10 \mathrm{C} 57 \mathrm{BL} / 6 \mathrm{~N}$ mice served as controls and were fed with pellets of the same composition but without the BACE1 inhibitor. C57BL/6N mice exhibit identical hearing loss profiles as the C57BL/6J strain (Kane et al., 2012). Immediately after treatment, auditory brainstem responses (ABR) were recorded and brains and cochleae were harvested and processed for analysis with SDS-PAGE/Western blot and immunohistochemistry, respectively.

Brain lysates. After the ABR recordings, narcotized C57BL/6N mice (controls and NB-360-treated) were immediately decapitated and brains were dissected. Only one hemisphere was used for protein extraction. Per milligrams tissue, $7 \mu$ l of Synaptic Protein Extraction Reagent (Syn-PER; Thermo Fisher Scientific) supplemented with Complete Mini EDTA-free protease inhibitor mixture (Roche) were added and brains were homogenized. Homogenates were centrifuged at $1200 \times g$ for $10 \mathrm{~min}$ at $4^{\circ} \mathrm{C}$ and cell debris was removed. Protein concentration was measured using the BCA Protein Assay Kit (Pierce). Samples were prepared in Syn-PER buffer, loading buffer (ProSieve ProTrack Dual Color Loading Buffer; Lonza), and $100 \mathrm{~mm}$ dithiothreitol (Sigma-Aldrich). $25 \mu \mathrm{g}$ of protein was loaded for SDS-PAGE/Western blot.

SDS-PAGE and Western blot. Samples were heated and maintained at $95^{\circ} \mathrm{C}$ for $5 \mathrm{~min}$. Proteins were separated in $10 \%$ TGX stain-free precast gels (Bio-Rad) and transferred onto PVDF membranes (Bio-Rad) using a wet blotting system (Criterion Blotter, Bio-Rad). Membranes were blocked in 5\% skim milk in TBS-T (10 mM Tris-HCl), $150 \mathrm{~mm} \mathrm{NaCl}$ and $0.1 \%$ Tween 20 ) for $1 \mathrm{~h}$ at room temperature. Primary antibodies were diluted in TBS-T with $0.1 \% \mathrm{NaN}_{3}$, and $1 \%$ BSA and incubated at $4^{\circ} \mathrm{C}$ overnight. After washing in TBS-T, secondary antibodies coupled to horseradish peroxidase (HRP) were incubated for $1 \mathrm{~h}$ at room temperature. Secondary antibodies were diluted in TBS-T with $5 \%$ skim milk. For detecting contactin2 (CNTN2), primary and secondary antibody solutions were prepared with $4 \%$ donkey serum instead of $1 \%$ BSA or $5 \%$ skim milk. The signal was visualized by enhanced chemiluminescence (ECL) using ECL Western Blotting Substrate (Bio-Rad) and imaged using the ChemoStar Imager (Intas). Membranes were stripped in $6 \mathrm{M}$ guanidine- $\mathrm{HCl}, 20 \mathrm{~mm}$ Tris, $0.2 \%$ Triton $\mathrm{X}-100, \mathrm{pH} 7.5$, and $0.8 \%$ $\beta$-mercaptoethanol for $20 \mathrm{~min}$ at room temperature. After blocking in $5 \%$ skim milk in TBS-T, membranes were reprobed. The antibodies used for Western blots were goat-anti-CNTN2 (R\&D Systems, AF4439), rabbit-anti-APP (C66, directed against the $\mathrm{C}$ terminus, Bhattacharyya et al., 2013), rabbit-anti-BACE1 (Abcam, ab108394), mouse-anti- $\beta$-actinHRP (Sigma-Aldrich, A3854), donkey-anti-goat-HRP (Jackson Laboratories, 705-035-147), and goat-anti-rabbit-HRP (Abcam, ab6721).

Auditory brainstem responses (ABRs) and otoacoustic emissions. ABRs were recorded in two different laboratories. In the first laboratory (see Fig. 1, lab 1) for recordings of ABR and distortion product otoacoustic emissions (DPOAE) mice were anesthetized with a combination of ketamine $(125 \mathrm{mg} / \mathrm{kg})$ and xylazine $(2.5 \mathrm{mg} / \mathrm{kg})$ intraperitoneally. The core temperature was maintained constant at $37^{\circ} \mathrm{C}$ using a heat blanket (Harvard Apparatus). For stimulus generation, presentation, and data acquisition, the TDT II System (Tucker Davis Technologies) run by BioSig 
software (The MathWorks). Tone bursts (4/6/8/12/16/24/32 kHz, $10 \mathrm{~ms}$ plateau, $1 \mathrm{~ms} \cos 2$ rise/fall) or clicks of $0.03 \mathrm{~ms}$ were presented at $40 \mathrm{~Hz}$ (tone bursts) or $20 \mathrm{~Hz}$ (clicks) in the free field ipsilaterally using a JBL 2402 speaker. The difference potential between vertex and mastoid subdermal needles was amplified 50000 times, filtered $(400-4000 \mathrm{~Hz})$ and sampled at a rate of $50 \mathrm{kHz}$ for $20 \mathrm{~ms}, 1300$ times, to obtain two mean ABR traces for each sound intensity. Hearing threshold was determined with $10 \mathrm{~dB}$ precision as the lowest stimulus intensity that evoked a reproducible response waveform in both traces by visual inspection by two independent observers.

In the second independent laboratory (see Fig. 1, lab 2, and Fig. 8), $\mathrm{ABR}$ in anesthetized mice were recorded using a custom build recording setup consisting of a low noise amplifier (JHM NeuroAmp 401, J. Helbig Messtechnik; amplification 10.000; band-pass filter $400 \mathrm{~Hz}$ to $2000 \mathrm{~Hz}$ and $50 \mathrm{~Hz}$ notch filter) and an analog-digital converter card (National Instruments) with a sampling rate of $20 \mathrm{kHz}$. Hearing thresholds were determined objectively using an algorithm where data are fitted to a generalized logistic function that was extended by an additive term representing the measured background noise.

For recordings of DPOAEs, continuous primary tones (frequency $\mathrm{f} 2=$ $1.2^{\star} \mathrm{f} 1$, intensity $12=11-10 \mathrm{~dB}$ SPL, duration $=16 \mathrm{~s}$ ) were delivered through the MF1 speaker system (Tucker Davis Technologies) and a custom-made probe containing an MKE-2 microphone (Sennheiser). The microphone signal was amplified (DMX 6Fire; Terratec) and the DPOAE amplitude at $2^{\star} \mathfrak{f} 2$-f1 was analyzed by fast Fourier transformation using custom-written MATLAB version 3 (The MathWorks). Sound pressure levels (SPLs) are provided in decibels SPL root mean square (RMS, tonal stimuli) or decibels SPL peak equivalent (clicks).

Immunohistochemistry. Immunohistochemistry was performed on formaldehyde-fixed whole-mount preparations and on formaldehydefixed cochlear cryo-sections of the apical turn of the organ of Corti (if not stated otherwise). Tissue was isolated from wild-type, and BACE1 ${ }^{-1-}$ mice (between P35 and P45), as well as from C57BL/6N from mice fed with pellets containing BACE1 inhibitor NB-360 and the untreated C57BL/6N control mice (P68-P77, Neumann et al., 2015). All mice were killed through decapitation. Cochleae were removed from the temporal bone and, after introduction of a small hole in the apical part, cochleae were placed in $2 \%$ paraformaldehyde for $2 \mathrm{~h}$ at $4^{\circ} \mathrm{C}$. For whole-mount immunostaining, the apical turn of the organ of Corti was dissected and separated from modiolus, stria vascularis and tectorial membrane. Specimens were mounted on Superfrost microscope slides (Thermo Scientific, 4951PLUS4). For cryo-sections, cochleae were decalcified in Rapid Bone Decalcifier (Thermo Scientific, 6764001) for 15 to $25 \mathrm{~min}$ at room temperature. After overnight incubation in $25 \%$ sucrose at $4^{\circ} \mathrm{C}$, cochleae were embedded in O.C.T. compound (Sakura Finetek, 4583). 10-12 $\mu \mathrm{m}$ cochlear cryo-sections were mounted on Superfrost microscope slides. Sections were stored at $-80^{\circ} \mathrm{C}$ until further processing.

Samples were blocked and permeabilized for $1 \mathrm{~h}$ at room temperature in a buffer containing $10 \%$ normal goat serum (NGS), $0.3 \%$ Triton $\mathrm{X}-100,20 \mathrm{~mm}$ phosphate buffer (PB), and $450 \mathrm{~mm} \mathrm{NaCl}$. Immunostaining was performed overnight at $4^{\circ} \mathrm{C}$ with the following primary antibodies (diluted in blocking solution): rabbit-anti-BACE1 (Abcam, ab108394; 1:50), guinea pig-anti-synapsin1,2 (Synaptic Systems, 106004; 1:500), rabbit-anti-KCNQ1 ( $\left.\mathrm{K}_{\mathrm{v}} 7.1\right)$ (Abcam, ab135737; 1:200), goatanti-prestin (N-20; Santa Cruz Biotechnology, sc-22692; 1:400), rabbitanti-KCNQ4 ( $\left.\mathrm{K}_{\mathrm{v}} 7.4\right)$ (H-130; Santa Cruz Biotechnology, sc-50417; 1:400), rabbit-anti-NF-200 (neurofilament heavy chain polypeptide, Sigma-Aldrich, N4142; 1:600) and chicken-anti-NF-H (neurofilament heavy chain polypeptide, Abcam, ab4680; 1:400), mouse-anti-CtBP2 (Cterminal binding protein; BD Bioscience, 612044; 1:200), rabbit-antiGluR2/3 (Glutamate receptor subunits 2/3, Merck, ab1506; 1:200), rabbit-anti-PSD95 (postsynaptic density 95, Abcam, ab18258; 1:200), mouse-anti-MBP (myelin basic protein; F-6; Santa Cruz Biotechnology, sc-271524; 1:400), and rabbit-anti-B-FABP (brain-type fatty acid binding protein, Kurtz et al., 1994, 1:1000). The primary antibodies were labeled for $90 \mathrm{~min}$ at room temperature with species-appropriate secondary antibodies coupled to Alexa Fluor dyes (Thermo Scientific and Abcam). Alexa-Fluor488-coupled phalloidin (Abcam, ab176753) was used to visualize actin-containing stereocilia. Nuclei were stained with 2 $\mu \mathrm{g} / \mathrm{ml}$ 4',6-Diamidine-2' - phenylindole dihydrochloride (DAPI, SigmaAldrich, D9542).

Confocal microscopy. Confocal imaging was performed with an upright LSM 710 Axio Examiner Z1 microscope using W-Plan-Apochromat $63 \times / 1.0$ M27 water-immersion objective (Carl Zeiss), as described previously (Wilke et al., 2014). Corresponding specimens of wild-type and BACE $1^{-1-}$ mice were imaged in parallel under identical experimental conditions (e.g., software and hardware settings). Fluorescent images represent maximum intensity projections of the $x-y$ plane generated from a minimum of five confocal planes (step size $1 \mu \mathrm{m}$ ) with Zen2009 software (Carl Zeiss).

Tissue preparation for transmission electron microscopy (TEM) analysis. Twelve mice inner ear specimens ( 6 wild-type and 6 BACE1 knock-out animals) were fixed in $2.5 \%$ glutaraldehyde and $2 \%$ paraformaldehyde buffered in sodium cacodylate $(0.1 \mathrm{M}, \mathrm{pH}=7.4)$ overnight at $4^{\circ} \mathrm{C}$. Tissue then was rinsed in sodium cacodylate buffer (SCB) and postfixed in 1\% osmium tetroxide in sodium cacodylate buffer for $3-4 \mathrm{~h}$ at $4^{\circ} \mathrm{C}$. Then samples were rinsed in SCB again and dehydrated in graded ethanol series and embedded in EPON resin. Ultrathin sections $(90 \mathrm{~nm})$ were cut on a Reichert Ultracut S microtome (Leica Microsystems) with an ultradiamond knife, mounted on dioxan-formvar-coated slot-grids (\#G2500C, Christine Gröpl, Elektronenmikroskopie, Tulln, Austria) and stained 35 min with $0.5 \%(\mathrm{w} / \mathrm{v})$ uranyl acetate, $\mathrm{pH} 4.4$ and $10 \mathrm{~min}$ with $3 \%(\mathrm{w} / \mathrm{v})$ lead citrate, pH 12 (Leica Ultrostainer, Leica Microsystems). The ultrathin sections were examined with a Philips CM 120 transmission electron microscope at $80 \mathrm{kV}$ (FEI) equipped with a MORADA digital camera (Olympus SIS).

Hair cell electrophysiology. Hair cell electrophysiology was performed as previously reported (Leitner et al., 2011). In brief, apical turns of the organ of Corti of wild-type and BACE1 ${ }^{-1-}$ mice (for inner hair cells (IHCs): P39-P42; for outer hair cells (OHCs): P14-P16) were isolated in extracellular solution containing the following (in $\mathrm{mm}$ ): $144 \mathrm{NaCl}, 5.8$ $\mathrm{KCl}, 1.3 \mathrm{CaCl}_{2}, 0.7 \mathrm{Na}_{2} \mathrm{HPO}_{4}, 0.9 \mathrm{MgCl}_{2}$, 5.6 glucose, $10 \mathrm{HEPES}, \mathrm{pH}$ adjusted to $7.4(\mathrm{NaOH})(305-310 \mathrm{mOsm} / \mathrm{kg})$. For recordings, specimens were transferred to an experimental chamber and continuously perfused with extracellular solution. If necessary, supporting cells were carefully removed with gentle suction through a patch pipette (pulled to a wider tip diameter for cleaning) to get access to the basal pole of IHCs and $\mathrm{OHCs}$ of the outermost row. Whole-cell patch-clamp recordings were performed at room temperature $\left(22-24^{\circ} \mathrm{C}\right)$ with an Axopatch $200 \mathrm{~B}$ amplifier (Molecular Devices) or an HEKA EPC10 USB patch-clamp amplifier controlled with HEKA PatchMaster software (both HEKA electronics). Patch pipettes were pulled from borosilicate glass (Sutter Instruments) and had a resistance of $2-3.5 \mathrm{M} \Omega$ after filling with intracellular solution containing the following (in $\mathrm{mM}$ ): $135 \mathrm{KCl}, 3.5 \mathrm{MgCl}_{2}, 2.4$ $\mathrm{CaCl}_{2}\left(0.1\right.$ free $\mathrm{Ca}^{2+}$ ), 5 EGTA, 5 HEPES, and $2.5 \mathrm{Na}_{2}-\mathrm{ATP}$ ( $\mathrm{pH}$ adjusted with $\mathrm{KOH}$ to $7.3 ; 290-295 \mathrm{mOsm} / \mathrm{kg}$ ) (Leitner et al., 2012). Voltageclamp recordings were low-pass filtered at $2.5 \mathrm{kHz}$ and sampled at $5 \mathrm{kHz}$. The series resistance $\left(R_{\mathrm{s}}\right)$ was kept $<6 \mathrm{M} \Omega$ and $R_{\mathrm{s}}$ was compensated throughout the recording (80-90\%). Steady-state current amplitudes were normalized to cell capacitance (current density; $\mathrm{pA} / \mathrm{pF}$ ), and membrane potentials shown were not corrected for liquid junction potentials (approx. $-4 \mathrm{mV}$ ). Steady-state current amplitudes were quantified at the end of an activating pulse. Time constants of current activation and deactivation were obtained from mono-exponential fits to the activating or deactivating current component. 10,10-bis(4-Pyridinylmethyl)-9(10 H)anthracenone dihydrochloride (XE991; Tocris Bioscience) was added to the extracellular solution at $20 \mu \mathrm{M}$ and was applied via a custom-made glass capillary pipette positioned in close proximity to the cell under investigation.

Recordings of prestin-associated nonlinear capacitance (NLC). Voltagedependent NLC was recorded from OHCs of wild-type and BACE1 $1^{-1-}$ mice (P31-P44), as previously reported (Huang and Santos-Sacchi, 1993; Oliver and Fakler, 1999). In brief, NLC was measured using a stimulus stair-step protocol from $-130 \mathrm{mV}$ to $+60 \mathrm{mV}$ (5 ms duration, $10 \mathrm{mV}$ increments). During recordings, OHCs were perfused with extracellular solution (see above) containing $20 \mu \mathrm{M}$ XE991 to inhibit predominant $\mathrm{K}_{\mathrm{V}} 7$ currents. Patch pipettes were filled with intracellular solution containing the following (in $\mathrm{mm}$ ): $110 \mathrm{CsCl}, 20 \mathrm{TEA}-\mathrm{Cl}, 3.5 \mathrm{MgCl}_{2}, 2.4$ 
$\mathrm{CaCl}_{2}, 2.5 \mathrm{Na}_{2}$-ATP, 5 HEPES, 5 EGTA, pH 7.3 (KOH), 290-295 mOsm/ $\mathrm{kg}$. Currents were recorded with an EPC-10 patch-clamp amplifier and PatchMaster software (HEKA), low-pass filtered at $10 \mathrm{kHz}$ and sampled at $100 \mathrm{kHz}$. Cell capacitance $\left(C_{\mathrm{m}}\right)$ was not compensated in the whole-cell configuration and the time constant $(\tau)$ of current decay was calculated from mono-exponential fits to the current transients in response to each voltage step. The input resistance $\left(R_{\text {in }}\right)$ was calculated from voltagedependent steady-state currents and integration of the current transients yielded the charge $(Q) . C_{\mathrm{m}}(i)$ at each voltage step was derived after correction of all voltages for $R_{\mathrm{s}}$ errors from the following formula: $C_{\mathrm{m}}(i)=$ $\left(R_{\mathrm{in}} / R_{\mathrm{m}}\right)^{2 *}\left(\mathrm{Q} / V_{\mathrm{c}}\right)$ where $R_{\mathrm{m}}$ is the membrane resistance and $V_{\mathrm{c}}$ is the holding potential. $R_{\mathrm{in}}$ and $R_{\mathrm{s}}$ were calculated as reported previously (Oliver and Fakler, 1999). The capacitance was fitted with a derivative of the

Boltzmann function: $C(V)=C_{\text {lin }}+\frac{Q_{\max }}{\alpha * e^{\frac{V-V_{1}}{\alpha}} *\left(1+e^{-\frac{V-V_{1}}{\alpha}}\right)^{2}}$, where

$C_{\text {lin }}$ is the residual, noncompensated linear capacitance, $V$ is the membrane potential, $Q_{\max }$ is the maximum voltage sensor charge moved through the membrane electrical field, $V_{1 / 2}$ is the voltage at half-maximal charge transfer and $\alpha$ is the slope factor of the voltage dependence. $C_{\text {lin }}$ was derived from the Boltzmann equation and reflected a measure for the surface membrane area of OHCs. As measure for prestin density in the $\mathrm{OHC}$ membrane, $Q_{\max }$ is presented as charge density $\left(Q_{\max } / C_{\text {lin }}\right)$. The nonlinear capacity (NLC) was normalized to $C_{\text {peak }}$ that denotes maximal voltagedependent capacitance at $V_{1 / 2}$.

FM1-43 entry assay. Organs of Corti of wild-type and BACE $1^{-1-}$ mice (P43-P45) were isolated in parallel and incubated for $45 \mathrm{~s}$ in extracellular solution containing $3 \mu \mathrm{M}$ FM1-43 (N-(3-(triethylammonium)propyl)-4(4-(dibutylamino)styryl)pyridinium, Thermo Scientific, F35355). After repeated washing, specimens were fixed with $2 \%$ paraformaldehyde for $1 \mathrm{~h}$ at $4^{\circ} \mathrm{C}$. After washing, organs were imaged on a LSM 710 Axio Examiner Z1 confocal microscope (Carl Zeiss) with identical experimental settings (FM1-43 entry assays were performed on 3 organ of Corti preparations from 3 mice per genotype).

Data analysis. Immunohistochemistry was analyzed with ImageJ, Zen2009 (Carl Zeiss) and IGOR Pro (Wavemetrics). Synapse counts (staining with antibodies directed against CtBP2, PSD95 or GluR2/3) were analyzed blinded for genotype by four to five independent researchers (see Figs. 5,6, and 8). The spatial extension of NF-200-positive immunosignals extending from inner spiral plexus (ISP) close to IHCs toward the osseous spiral lamina (OSL) was analyzed manually using ImageJ and also blinded for genotype (see Fig. 7C). Electrophysiological recordings were analyzed with PatchMaster (HEKA) and IGOR Pro (Wavemetrics), as well as custom-made programs written in Python. Fiji software was used for densitometric analysis of Western blots (Schindelin et al., 2012) and data analysis was performed using OriginPro version 9.0 (OriginLab).

Statistical analysis. Statistical analysis was performed using two-tailed Student's $t$ test or Wilcoxon-Mann-Whitney test. Significance was assigned at $p \leq 0.05\left({ }^{*} p \leq 0.05 ;{ }^{* *} p \leq 0.01 ;{ }^{* *} p \leq 0.001\right)$. Data are presented as mean \pm SEM. In electrophysiological experiments, $n$ represents the number of individual cells and accordingly the number of independent experiments.

\section{Results \\ Deletion of Bace1 causes hearing impairment in mice}

To assess auditory function of BACE $1^{-1-}$ mice, we recorded ABRs and DPOAEs in 5- to 6-week-old mice compared with wild-type littermates of the same age. ABR recordings were performed independently in two different laboratories yielding qualitatively the same results (Fig. 1). ABR thresholds to tone bursts between $4 \mathrm{kHz}$ and $32 \mathrm{kHz}$ (Fig. 1A) and click stimulation (Fig. $1 B, F$ ) were significantly elevated by $\sim 20$ to $40 \mathrm{~dB}$ SPL in BACE $1^{-1-}$ mice. All ABR waves that report on synchronous activity in response to onset of sound (click stimulus) in spiral ganglia neurons (SGN; wave I) and in neurons of the auditory brainstem (waves II-V) were strongly reduced in amplitude in
BACE1 ${ }^{-1-}$ mice when compared with wild-type controls (Fig. $1 B, C, F)$. The latencies of all ABR waves were increased concurrently, underscoring the auditory deficits in the mutant mice (Fig. $1 B, D, G$ ). In addition, DPOAE intensities were substantially reduced in BACE1 ${ }^{-1-}$ mice (Fig. $1 E$ ). Together, these data indicate a loss in auditory sensitivity due to impaired sound processing in the cochlea of BACE1 ${ }^{-/-}$mice.

\section{BACE1 is expressed in SGN and olivocochlear efferent terminals}

We therefore analyzed expression and distribution of BACE1 with immunohistochemistry using cochlear cryo-sections and whole-mount preparations of the organ of Corti. In 6 to 7 weeks old wild-type (BACE1 ${ }^{+/+}$) mice, strong anti-BACE1 immunosignals were detected in cell bodies of neurons in the spiral ganglion (Fig. 2A), indicating expression of BACE1 in afferent auditory neurons. In the organ of Corti, anti-BACE1 immunosignals were found in small structures close to the basal pole of IHCs and OHCs, respectively (Fig. 2C). Strict colocalization with anti-synapsin1,2 immunofluorescence indicated that these BACE1-positive boutons are olivocochlear efferent terminals (Fig. 2C) (Vogl et al., 2015). Specific expression of BACE1 in these afferent and efferent structures was confirmed by strong reduction of the anti-BACE1 immunofluorescence in the spiral ganglion and the efferent terminals of $\mathrm{BACE} 1^{-1-}$ mice (Fig. $2 B, D)$. In contrast, only faint and likely unspecific anti-BACE1 immunosignals were present in the stria vascularis of wild-type and BACE1 ${ }^{-1-}$ mice (Fig. $2 E$ ), suggesting that BACE1 expression is either absent in the stria vascularis or below detection threshold. Expression of KCNQ1 ( $\left.\mathrm{K}_{\mathrm{V}} 7.1\right)$ channels in marginal cells appeared identical in wild-type and knock-out mice (Fig. 2F).

\section{Integrity of hair cell structure and function in BACE1 $^{-1-}$ mice}

The in vivo electrophysiological data indicated that the hearing impairment of BACE1 ${ }^{-/-}$mice originated from impaired signal processing in the auditory periphery, implicating a loss or dysfunction of hair cells, of synaptic transmission, or of signal propagation along auditory neurons. We therefore examined the structural integrity of the cochlea of mice matched to the age of mice analyzed in the ABR experiments with immunolabeling and confocal microscopy. We did not detect any structural changes in the organ of Corti or hair cell loss in BACE1 ${ }^{-1-}$ mice (Fig. $3 A, B$; $n=4)$. When stained with fluorescently labeled phalloidin, hair bundles of IHCs and OHCs appeared normal in BACE1 ${ }^{-1-}$ mice (Fig. $3 A, B$ ). To analyze whether hair cell function was normal in BACE1 $1^{-1-}$ mice, we examined the physiology of hair cells in vitro. Function of the mechano-electrical transduction (MET) machinery was probed with the lipophilic styryl dye FM1-43 known to enter hair cells through functional MET channels (Gale et al., 2001; Meyers et al., 2003). Uptake of FM1-43 following brief $45 \mathrm{~s}$ application to acutely isolated explants of the organ of Corti was measured by confocal microscopy. FM1-43 accumulation in IHCs and OHCs was homogenous and indistinguishable between explants from wild-type and BACE1 ${ }^{-1-}$ mice consistent with a normal function of MET channels in the knock-out mice (Fig. 3C). Because reduced DPOAEs point toward $\mathrm{OHC}$ dysfunction, we evaluated the physiology of $\mathrm{OHC}$ in $\mathrm{BACE} 1^{-1-}$ mice by analyzing expression and function of two essential OHC proteins: prestin, underlying $\mathrm{OHC}$ electromotility, and voltagegated $\mathrm{K}^{+}$channel $\mathrm{K}_{\mathrm{v}} 7.4$ (KCNQ4), known to dominate the basolateral OHC conductance (Kharkovets et al., 2006; Johnson et al., 2011). Immunohistochemistry showed that both, expres- 


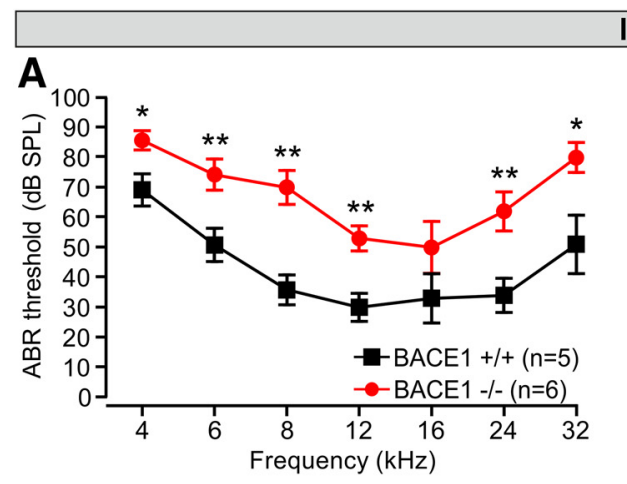

lab 1

C

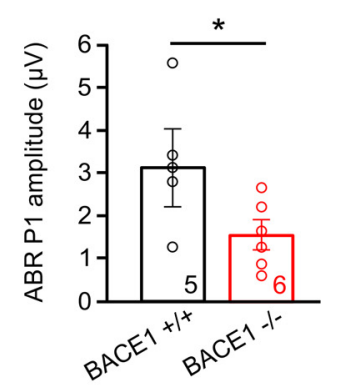

D

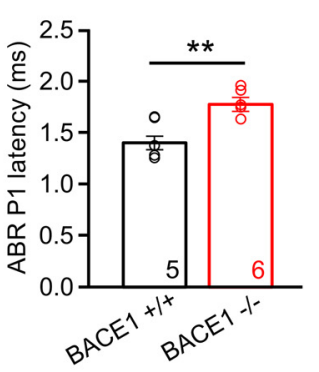

\section{B}

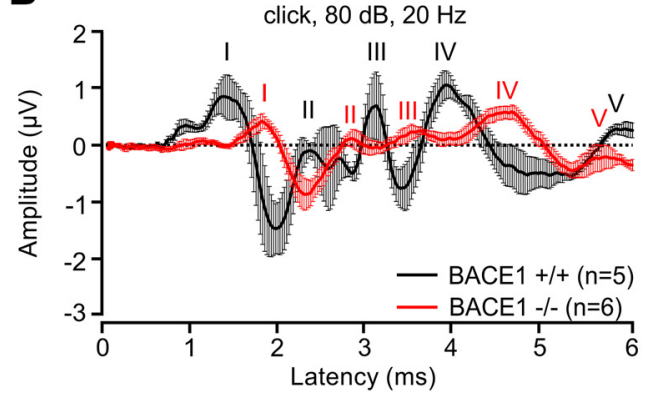

E

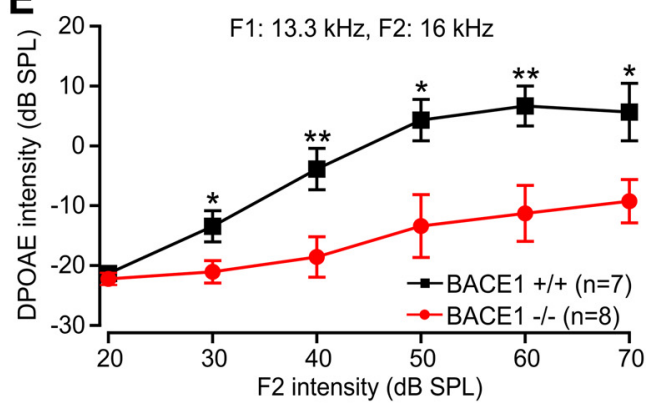

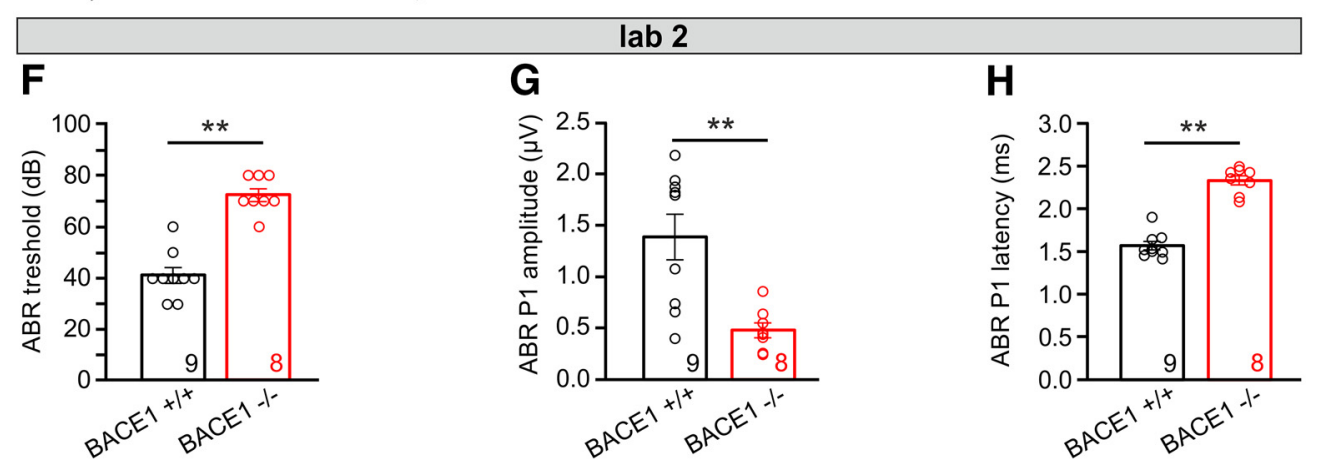

Figure 1. Deletion of BACE1 causes hearing impairment. $A, A B R$ thresholds to tone bursts between $4 \mathrm{kHz}$ and $32 \mathrm{kHz}$ were significantly elevated by $\sim 20$ to $40 \mathrm{~dB}$ SPL in BACE1 $-/-$ mice $(n=$ 6) compared with wild-type controls $(n=5)$. Note that there was no statistical difference between genotypes at $16 \mathrm{kHz}$ in these experiments. $\boldsymbol{B}-\boldsymbol{D}$, In $B A C E 1-1-$ mice, all $A B R$ waves were reduced in amplitude and latencies were increased. $B$, Shows summarized ABR waveforms in response to click stimulation for BACE1 ${ }^{-1-}$ (red; $\left.n=6\right)$ and wild-type $($ black; $n=5)$ mice $(80 \mathrm{~dB}$ peak equivalent, $20 \mathrm{~Hz}$ stimulation rate). Matching the overall loss of sensitivity, ABR wave I showed (C) reduced amplitude and (D) increased latencies in BACE1 ${ }^{-/-}$mice. Amplitudes and latencies were analyzed in recordings as shown in B. E, DPOAE intensities were also reduced in BACE1 ${ }^{-1-}$ mice $(n=8)$ compared with wild-type mice $(n=7)$ (F1 and F2 as indicated). Mice of both sexes were used 5- 6 weeks after birth. $\boldsymbol{F}-\boldsymbol{H}$, Auditory brainstem responses following click stimulation were recorded in wild-type and BACE1 ${ }^{-1-}$ mice by a second independent laboratory (lab 2 ). Also in these recordings, in BACE1 ${ }^{-1-}$ mice, $(\boldsymbol{F})$ the $A B R$ thresholds were elevated, $(\boldsymbol{G})$ the amplitude of ABR wave I (P1) was decreased and $(\boldsymbol{H})$ the latency of wave I was increased compared with wild-type mice. Amplitude of ABR wave I was analyzed at $16 \mathrm{kHz}$ ( $90 \mathrm{~dB} \mathrm{SPL}$ ) and wave I latency was quantified at $16 \mathrm{kHz}$ ( $20 \mathrm{~dB}$ over threshold). Mice of both sexes were used $6-7$ weeks after birth. $n=9$ for wild-type and $n=8$ for BACE1 ${ }^{-1-}$ mice. Note that ABR recordings with pure tones performed in an independent laboratory (lab 1$)$ yielded essentially the same results $(\boldsymbol{A}-\boldsymbol{E}$ ). All data are represented as mean $\pm \mathrm{SEM},{ }^{*} p<0.05,{ }^{* *} p<0.01$ ( $p$-values from two-tailed two-sample $t$ test). Open symbols in $\boldsymbol{C}, \boldsymbol{D}$, and $\boldsymbol{F}$ - $\boldsymbol{H}$ show individual values for each animal.

sion levels and the characteristic subcellular distribution of prestin (Fig. 3D) and KCNQ4 (K 7.4$)$ (Fig. 3E), appeared normal in $\mathrm{OHCs}$ of adult BACE1 ${ }^{-/-}$mice (P35-P45). Functionally, amplitude and voltage-dependent features of prestin-mediated nonlinear capacitance were indistinguishable between OHCs from wild-type and BACE1 $1^{-1-}$ mice (Fig. $4 A$ ). Similarly, in OHCs KCNQ4-mediated currents quantified as the XE991-sensitive steady-state outward current at $-60 \mathrm{mV}$ (Oliver et al., 2003; Leitner et al., 2011) were indistinguishable between wild-type $(33.6 \pm 4.8 \mathrm{pA} / \mathrm{pF} ; n=6)$ and $\mathrm{BACE} 1^{-/-}$mice $(34.5 \pm 5.1$ $\mathrm{pA} / \mathrm{pF} ; n=6$; Fig. $4 B$ ). Other functional features of OHCs including resting membrane potential (Fig. $4 C$ ), kinetics of KCNQ4 currents (Fig. 4D) and cell capacitance (Fig. 4E) were unchanged in BACE1 $1^{-1-}$ mice. In summary, these experiments did not reveal major alterations of $\mathrm{OHC}$ physiology in $\mathrm{BACE} 1^{-/-}$mice.
Similarly, in IHCs of BACE1 $1^{-/-}$mice $\mathrm{K}^{+}$current amplitudes (Fig. $4 F$ ), cell capacitance (Fig. $4 G$ ), and resting membrane potential (Fig. 4H) were also the same as in wild-type.

\section{Normal organization of afferent ribbon synapses in}

BACE1 ${ }^{-1-}$ mice

Given the apparent integrity of hair cells, we next analyzed the afferent synapses of IHCs. Structural alignment and integrity of the IHC-to-SGN synapse were assessed in wild-type and BACE $1^{-/-}$mice by blinded counting of double-labeled presynaptic and postsynaptic structures in apical turns of the cochlea (Figs. 5, 6). Synapses were identified as juxtaposed presynaptic ribbons and postsynaptic AMPA receptor clusters characterized by staining with antibodies against CtBP2 and GluR2/3, respectively (Khimich et al., 2005). We found $11.8 \pm 0.4$ ribbons per 
IHC and $11.9 \pm 0.4$ GluR2/3 clusters in wild-type mice that importantly were located in close proximity $(n=41$ IHCs from 6 preparations of 3 mice; Fig. $5 A, C$ ), just as previously reported for wild-type mice (e.g., Vogl et al., 2017). Synapse counts were not altered in BACE1 ${ }^{-1-}$ mice, with $11.7 \pm 0.4$ ribbons per IHC and $11.8 \pm 0.4$ GluR2/3 clusters nearby ( $n=57$, IHCs from 6 preparations of 6 mice; Fig. $5 B, C$ ). GluR2/3 and CtBP2 immunofluorescent spots were juxtaposed in wild-type and BACE1 ${ }^{-/-}$mice demonstrating identical counts of ribbonoccupied IHC synapses in both genotypes. Similarly, presynaptic ribbons in OHCs were also unchanged in number and morphology in BACE1 ${ }^{-/-}$compared with wild-type mice (Fig. 5D).

\section{Disorganization of (afferent) SGN \\ fibers and ectopic overexpression of PSD95 in BACE1 ${ }^{-1-}$ mice}

We next examined the architecture of nerve fibers in the organ of Corti using an antibody directed against the spiral ganglion fiber marker neurofilament protein $200 \mathrm{kDa}$ (NF-200). In doing so, we identified three distinct abnormalities in cochleae of BACE1 ${ }^{-/-}$mice:

(1) Nerve fibers in the IHC region displayed higher anti-NF-200 immunofluorescence, appeared disorganized and enlarged, and occupied far more space in the synaptic area than in wild-type mice. Also, NF-200-stained fibers appeared somewhat thicker than in wild-type mice (Fig. 6A, $B$ ).

(2) To analyze the postsynaptic assembly in more detail, we stained presynaptic CtBP2 together with the postsynaptic scaffolding protein PSD95 and NF-H in acutely isolated organ of Corti explants. In wild-type mice, CtBP2- and PSD95positive clusters precisely juxtaposed, i.e., PSD95 was exclusively localized in close proximity to the presynaptic region of IHCs (Fig. $6 C, E$ ). In contrast, in BACE1 ${ }^{-1-}$ mice the number of PSD95-positive clusters was significantly higher than in wildtype mice ( $p \leq 0.001$ ), by far exceeding the (unchanged) number of CtBP2-positive IHC ribbons ( $p \leq 0.001$; Fig. $6 D, E)$. This increased number of PSD95 clusters indicated a mismatch of presynaptic and postsynaptic structures in BACE1 ${ }^{-1-}$ mice. The additional PSD95 clusters were preferentially located (far) outside the synaptic region and thus were not associated with presynaptic IHC ribbons (Fig. $6 D, F)$. In BACE1 ${ }^{-/-}$mice, the ectopic PSD95 clusters were distributed completely across the enlarged nerve fibers in the IHC region defined by NF-H reactivity (Fig. 6D,F). In contrast, in wild-type mice the PSD95 clusters were all located in close proximity to presynaptic IHCs (Fig. 6C,F). Thus, loss of BACE1 expression in the cochlea caused enlargement of SGN fibers and expression of PSD95 unmatched by CtBP 2 reactivity. In contrast, expression of GluR2/3 expression in the postsynapse appeared normal (cf. Fig. 5C).

(3) In BACE1 ${ }^{-/-}$mice, NF-200-positive patches with high immunofluorescence appeared in the osseous spiral lamina (OSL) region between IHCs and the modiolus (Fig. 6B). These structures appeared as enlargements of the afferent fibers. As we did not detect anti-PSD95 immunosignals in these structures, we consider that these patches did not represent ectopically formed postsynaptic compartments (anti-PSD95 stainings not shown). These patches were entirely absent in wild-type cochleae (Fig. $6 A, B)$.

\section{Demyelination of peripheral auditory nerve fibers in $\mathrm{BACE}^{-/-}$mice}

As the NF-200 antibody preferentially recognizes nonmyelinated segments of peripheral neurites (Kujawa and Liberman, 2009; Lin et al., 2011), we reasoned that the observed excessive NF-200 staining pattern may indicate altered myelination of auditory afferent nerve fibers. We thus examined myelination of SGN fi- 


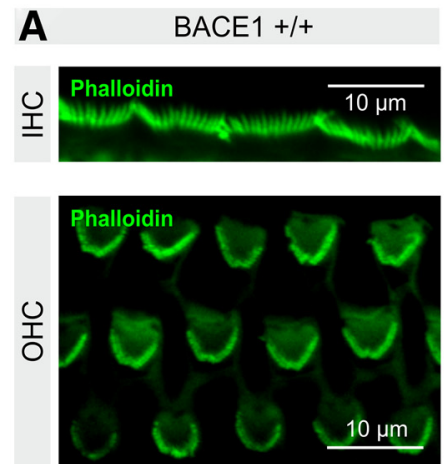

C

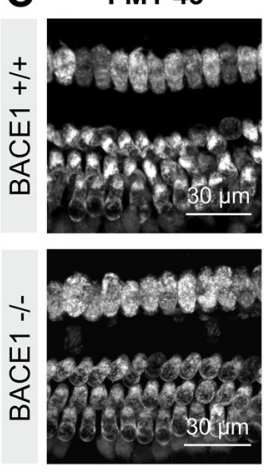

D
B
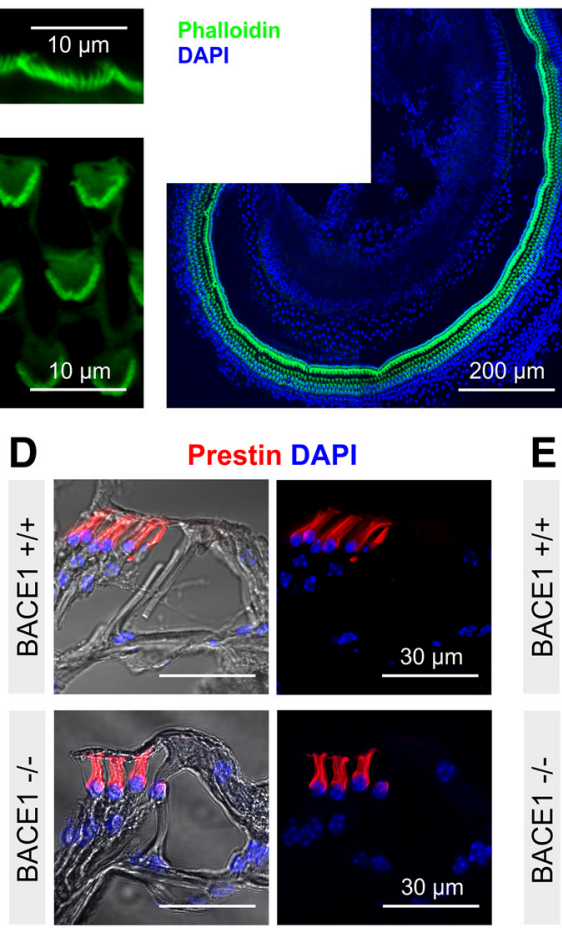

Prestin DAPI

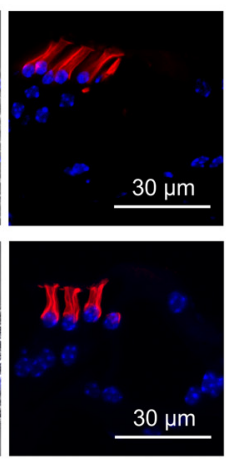

BACE1 -/-

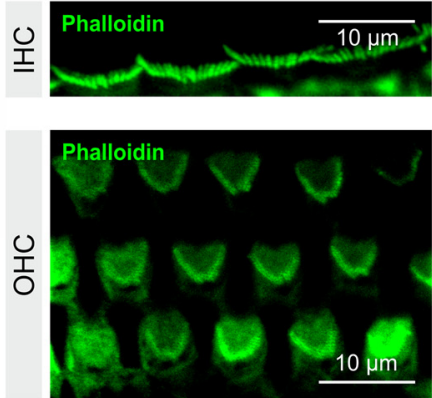

E

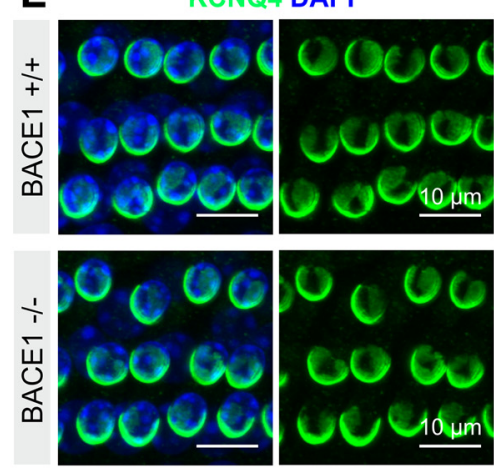

Figure 3. Normal hair cell function in BACE1 ${ }^{-1-}$ mice. $A, B$, The images show representative confocal projections of whole-mount preparations of apical turns of the organ of Corti isolated from a $(\boldsymbol{A})$ wild-type and $(\boldsymbol{B})$ BACE1 ${ }^{-1-}$ mice. Tissue was stained with fluorescently labeled phalloidin (green) and DAPI (blue) to visualize actin-containing stereocilia and the nuclei, respectively. We did not detect any signs of hair cell degeneration or altered hair bundle morphology in the organ of Corti of BACE1 ${ }^{-1-}$ mice. (C) FM1-43 entry into IHCs and $0 \mathrm{HCs}$, as detected by comparing intensity of FM1-43-associated fluorescence in hair cells after 45 s exposure, was the same in BACE1 ${ }^{+1+}$ (top) and BACE1 ${ }^{-1-}$ mice (bottom). These experiments were performed on 3 organ of Corti preparations from three mice per genotype mice and did not reveal any difference of FM1- 43 entry into hair cells of both genotypes. $D$, Cryosections of the cochlea stained with anti-prestin antibodies revealed that localization and expression of prestin (red) in the lateral membrane of OHCs was indistinguishable between wild-type (top) and BACE 1 - /- (bottom) mice. The image depicts a representative section through the apical cochlear turn. $\boldsymbol{E}$, Expression and localization of KCNQ4 (K 7.4 ) channels in 0 HCs was the same in wild-type and BACE1 ${ }^{-/-}$(whole-mount preparations of the organ of Corti stained with anti-KCNQ4 antibodies (green) and DAPI (blue)). $\boldsymbol{A}-\boldsymbol{E}$ show representative confocal projections of $z$-stacks of tissue stained with the given primary antibodies in the apical turn of Corti. All tissue was isolated from mice of either sex at the age of P35-P45.

bers in whole-mount explants of the organ of Corti using an antibody directed against myelin basic protein (MBP). In wildtype mice, the anti-MBP-antibody strongly and homogenously labeled most fibers in the OSL along their entire length, except for the most distal segment close to IHCs (Fig. 7A). This pattern is consistent with the fact that in the normal adult mouse cochlea, $\sim 90 \%$ of the distal afferent nerve fibers are myelinated (Nayagam et al., 2011). Thus, we presume that most of these myelinated fibers recognized by the anti-MBP antibody are type I afferents. In cochleae from adult $\mathrm{BACE} 1^{-1-}$ mice, the MBP staining was markedly reduced, as by far fewer fibers showed myelination at all and, if detectable, myelination did not extend all the way to the distal endings in the majority of those fibers (Fig. $7 B$ ). Indeed, when taking NF-200-positive immunostaining as measure for the traveling distance of fibers without myelination, we found that in wild-type mice the myelination of fibers traveling toward the hair cell region ended $\sim 40 \mu \mathrm{m}$ away from IHCs in the OSL close to the habenula perforata (Fig. $7 B, C$ ). In contrast, in BACE1 ${ }^{-1-}$ mice, NF-200-positive immunoreactivity extended approximately twice further from the inner spiral plexus (ISP) toward the spiral ganglion ( $p \leq 0.001 ; n=80$ fibers from 4 different animals per genotype; Fig. 7C). To substantiate our findings, we investigated ultrathin $(90 \mathrm{~nm})$ sections of the adult cochlea with transmission electron microscopy (TEM). In BACE1 ${ }^{-1-}$ mice, the myelination of the SGN cell bodies and surrounding fibers was mostly absent (Fig. 7D, red arrows), and the thickness of the myelin layers of the nerve fibers in the OSL was substantially reduced compared with the wild-type mice (Fig. 7E). Furthermore, in contrast to wild-type mice, many nerve fibers in the OSL were not myelinated (Fig. 7E, red asterisks). This supports the finding that myelination of the peripheral auditory fibers was decreased in BACE1 ${ }^{-/-}$mice.

Together, our data demonstrated severe disorganization of peripheral fibers of (type I) afferent neurons in BACE1 ${ }^{-/-}$mice, strongly enlarged endings, supernumerary postsynaptic sites, and impaired myelination. We therefore posit that BACE1 is essential to ensure normal architecture and, myelination of distal auditory fibers in the cochlea.

Treatment with BACE1 inhibitor does not cause hearing loss Given that BACE1 is widely recognized as a prime drug target for the prevention and treatment of $\mathrm{AD}$, we wondered whether chronic pharmacological suppression of BACE1 activity in normal mice would carry the risk of unwanted side effects in the auditory system. To address this translationally important question, we treated 1-month-old wild-type mice with the established blood-brain barrier permeable BACE1 inhibitor NB-360 (Neumann et al., 2015). The drug was administered for 6 weeks, which, in a mouse model of $\mathrm{AD}$, proved sufficient to reduce $\mathrm{A} \beta$ fibrils in cortical tissue and to rescue neuronal hyperactivity, impaired circuit function and memory deficits (Keskin et al., 2017). Suppression of BACE1 activity by NB-360 was indicated by the following findings. The fur of treated mice lost its homogeneous black color, thereby exhibiting more or less pronounced patches 
A1

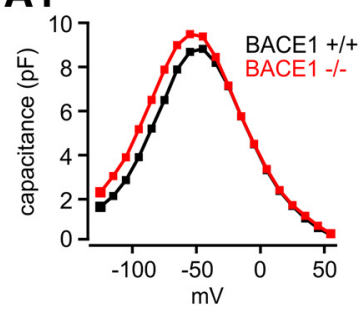

옹

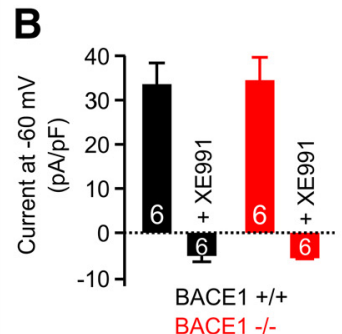

F

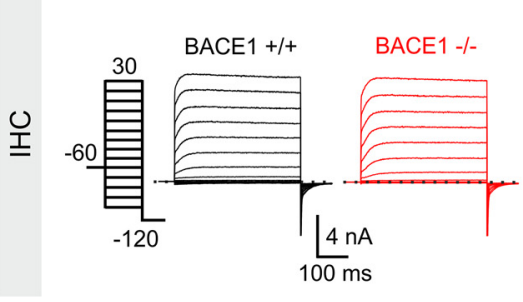

A2

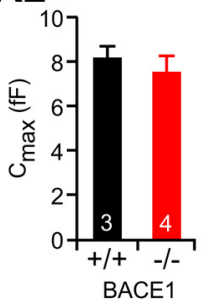

C

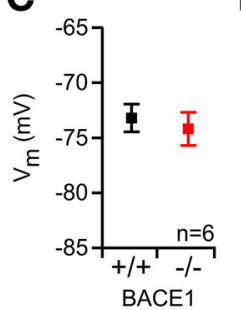

D
A3

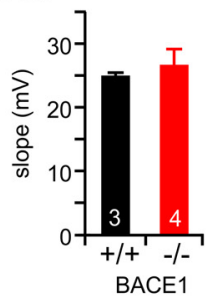

A4

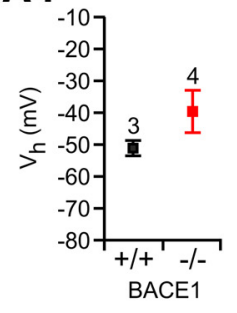

E

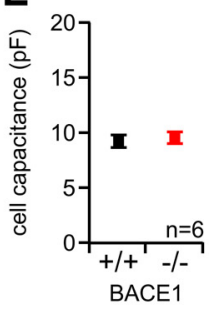

\section{G}
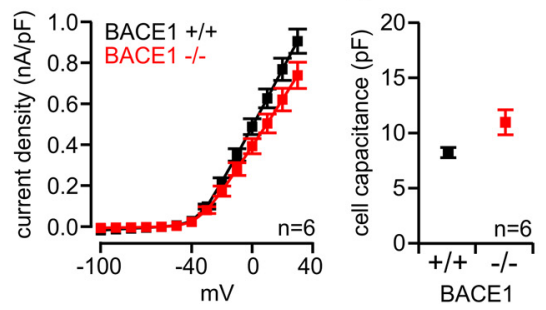

H

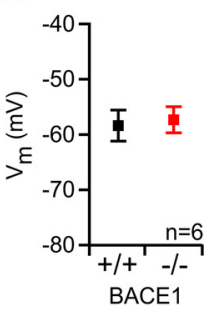

Figure 4. Normal biophysical properties of prestin and hair cell $\mathrm{K}^{+}$currents in BACE1 ${ }^{-/-}$mice. We did not detect any differences in the properties of prestin or the $\mathrm{K}^{+}$currents expressed in hair cells between wild-type and BACE1 ${ }^{-1-}$ mice. $\boldsymbol{A}-\boldsymbol{E}$ summarize for $\mathrm{OHCS}(\boldsymbol{A})$ amplitude $\left(\boldsymbol{A} \mathbf{1}\right.$, representative capacitance recordings; $\boldsymbol{A 2}$, summarized maximum capacitance $\left.\boldsymbol{C}_{\text {max }}\right)$ and voltagedependent features of prestin-mediated nonlinear capacitance ( $\boldsymbol{A}$ 3, summarized slope; $\boldsymbol{A}$ 4, summarized $\left.V_{\mathrm{h}}\right),(\boldsymbol{B}) \mathrm{K}_{\mathrm{v}} 7.4$-mediated currents quantified as XE991-sensitive steady-state outward current at $-60 \mathrm{mV},(\boldsymbol{C})$ resting membrane potential, $(\boldsymbol{D})$ activation (left) and deactivation (right) kinetics of XE991-sensitive currents and $(\boldsymbol{E})$ cell capacitance. Note that all parameters were the same in $0 \mathrm{HCS}$ of BACE1 ${ }^{+/+}$and BACE1 ${ }^{-/-}$mice. $\boldsymbol{F}-\boldsymbol{H}$ show that also in $\mathrm{IHCS}(\boldsymbol{F})$ whole-cell current densities, $(\boldsymbol{G})$ cell capacitance and $(\boldsymbol{H})$ resting membrane potentials were the same in both genotypes. $\boldsymbol{F}$, Representative current recordings. $\boldsymbol{F}-\boldsymbol{H}$ summarize the recordings of $\mathrm{IHCs}$ isolated from mice of both genotypes $(n=6$ for each genotype). All tissue was isolated from mice at the age of $\mathrm{P} 39-\mathrm{P} 42$ (IHC) and P14 -P16 (OHC). All hair cells were recorded from the apical turn of the organ of Corti.

of gray (Fig. 8A) (Shimshek et al., 2016; Hartmann et al., 2018). Western blot analysis of amyloid precursor protein (APP) and contactin-2 (CNTN2 (Gautam et al., 2014), two known BACE1 substrates, demonstrated a significant increase of the respective, unprocessed full-length protein (Fig. $8 B, C$ ), consistent with a previous report on NB-360 (Neumann et al., 2015). In stark contrast to the pronounced hearing impairment of BACE1 ${ }^{-1-}$ mice, NB-360-treated wild-type mice performed just as well in ABR recordings as their drug-free counterparts (Fig. $8 D$ ). As almost predicted by the normal ABR results from the treated mice, NB360 administration also did not produce the aberrant histological features in the cochlea that we had identified in BACE1 ${ }^{-1-}$ mice. Thus, we did not observe differences between NB-360-treated and control mice at presynaptic or postsynaptic sites of the IHCto-SGN synapse (Fig. $8 E$ ) and we observed no ectopically expressed PSD 95 clusters as seen in BACE1 ${ }^{-/-}$mice (Fig. $8 F$ ). Also, staining against NF-200 and MBP showed that NB-360 did not affect axonal organization and myelination (Fig. $8 G, H$ ). It therefore appears safe to conclude that the auditory phenotype of BACE1-deficient mice including its neuropathological underpinnings is not reproduced by prolonged systemic NB-360 administration in wild-type mice.

\section{BACE1 knock-out mice do not develop proper myelination in the cochlea}

The lack of an auditory phenotype of NB-360-treated adult wildtype mice suggested to us that the hearing loss of the mutant line might be of developmental origin. To explore the role of BACE1 in postnatal cochlear wiring, we compared the time course of myelination in the apical turn of the organ of Corti in wild-type and BACE1-deficient mice between postnatal days 5-15 (Fig. $9 A$ ), when cochlear BACE1 levels are invariably high (Shen et al., 2015). In wild-type mice, considerable proximal myelination was already present at P5-P6. At P8, the myelin sheath extended distally to the habenula perforata in some fibers, and myelination reached mature levels by the end of the second postnatal week (Fig. 9A, top; cf. Fig. $7 A$ ). In stark contrast, BACE1 ${ }^{-1-}$ mice did not show any myelination in the cochlea at the end of the first postnatal week, and at P14, we detected only faint anti-MBP signals in proximal regions of SGN fibers (Fig. 9A, bottom). Thus, the developmental myelination in the cochlea of BACE1-deficient mice was markedly delayed, and axonal ensheathment remained immature even in adulthood (Fig. 7B). The observed enlargement and disorganization of fibers in

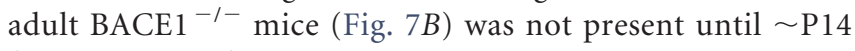
(Fig. 9A, arrows).

In the apical turn of the cochlea, the postsynaptic compartment appeared normal (Fig. 9A,B) until at least P14-P15 (Fig. $6 B)$. However, in the base of the cochlea, SGN fiber terminals were already abnormally swollen around the same time point (Fig. 9B), indicating a progression of deterioration from the cochlear base to the apex that follows the sequence of tonotopic myelination in humans (Ray et al., 2005). 

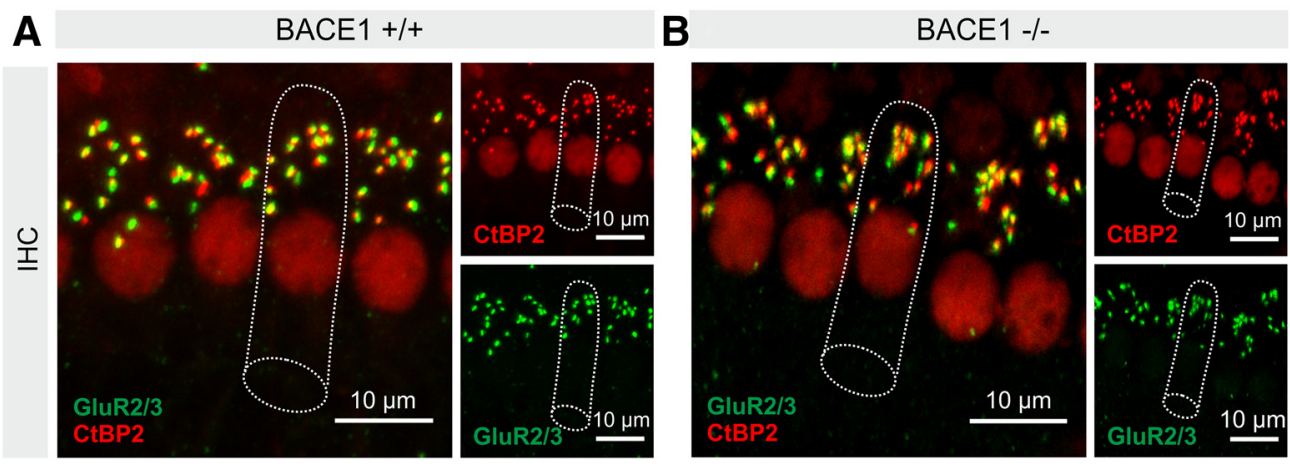

C

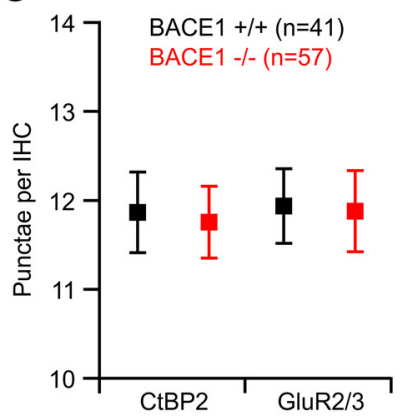

D

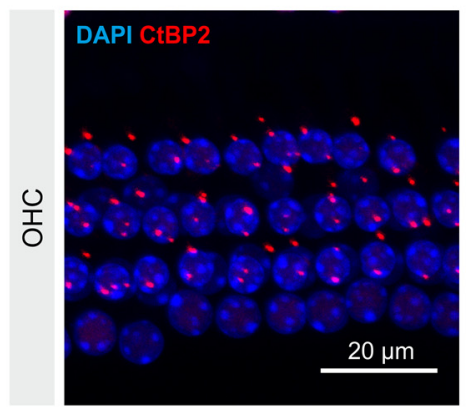

BACE1 -/-

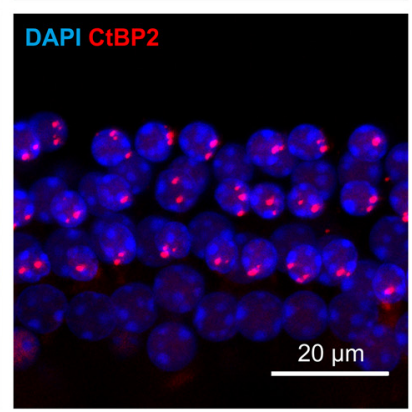

Figure 5. The architecture of ribbon synapses appears normal in $B A C E 1^{-1-}$ mice. $A, B$, Representative maximum intensity projections of confocal $z$-stacks from the IHC region in the organ of Corti of the apical turn of $(\boldsymbol{A})$ wild-type and $(\boldsymbol{B})$ and BACE1 ${ }^{-1-}$ mice stained with antibodies directed against presynaptic CtBP2 (red) and postsynaptic GluR2/3 (green). Dotted lines visualize individual IHCs in the region. $C$, CtBP2 and GluR2/3 puncta were quantified by blinded counting of immunopositive clusters from images as shown in (A+B) in BACE $1^{+/+}(n=41$ cells of 3 mice) and BACE1 ${ }^{-1-}$ mice ( $n=57$ cells of 3 mice). There was no significant difference between genotypes. $\boldsymbol{D}$, There was no obvious difference in the number of CtBP2-positive clusters in $0 \mathrm{HCs}$ of BACE1 ${ }^{+/+}$(left) and BACE1 ${ }^{-/-}$(right) mice. D, Representative confocal projections through the $0 \mathrm{HC}$ region in the apical turn of BACE1 ${ }^{+/+}$(left) and BACE1 ${ }^{-/-}$(right) mice stained with anti-CtBP2 antibodies (red) and DAPI (blue).

Neuregulin signaling is impaired in BACE1 knock-out mice NRG1 is an important substrate of BACE1. Upon BACE1 cleavage, its N-terminal region is released and binds to ErbB receptors (for review, see $\mathrm{Hu}$ et al., 2016). As a consequence of impaired NRG1-ErbB-signaling, myelination of peripheral nerves is compromised in BACE1 ${ }^{-1-}$ mice (Hu et al., 2006; Willem et al., 2006). In the cochlea, NRG1 is expressed in SGNs (Morley, 1998; Hansen et al., 2001; Stankovic et al., 2004) and signals to cochlear Schwann cells containing ErbB2 and ErbB3 receptors (Hansen et al., 2001). Activated NRG1 type III is a key regulator of myelin thickness in the peripheral nervous system (Taveggia et al., 2005; Velanac et al., 2012). Type-III NRG1 ${ }^{+/-}$mice have slightly increased hearing thresholds at the age of 12 months (Jin et al., 2011). NRG1 is therefore a candidate BACE1 substrate in the cochlea that, when incompletely processed, might cause the observed hypomyelination. To substantiate this, we examined the cochlea of heterozygous $N r g 1-\beta$ allele mutant mice that carry only one intact copy of Nrg1. We restricted our analyses to heterozygous mice, as the homozygous $\mathrm{Nrg} 1-\beta$ mutation is lethal. We analyzed myelination of SGN fibers and nerve fiber architecture using anti-MBP and anti-NF-200-antibodies, respectively. Further, we used a B-FABP-antibody (brain-type fatty acid binding protein, Kurtz et al., 1994), that recognizes nonmyelinating glial cells and labels the synaptic region of inner hair cells devoid of myelin. In wild-type animals, the distal unmyelinated part of SGN fibers and the postsynaptic compartment was completely covered by FABP-positive glia cells (Fig. 10A,B). In BACE $1^{-/-}$mice, the FABP-positive zone extended considerably more proximally covering a large part of unmyelinated axons and the enlarged postsynaptic region (Fig. 10B). Nrg1- $\beta$-hetero- zygous mice show a similar, but less pronounced phenotype exhibiting the same neuropathological hallmarks, namely enlarged and disorganized postsynaptic compartments (NF200), fiber hypomyelination (MBP) and an extended axonal area covered by unmyelinated glia that stain for FABP (Fig. 10). The results strongly suggest that impaired NRG1-ErbBsignaling is responsible for the aberrant cochlear wiring in BACE1 knock-out mice.

\section{Discussion}

Our study establishes hearing loss as a novel phenotype of BACE1-deficient mice. The high expression levels of BACE1 in neurons of the spiral ganglion and in olivocochlear terminals, together with the conspicuous neuropathology in the cochlea and the related abnormalities in the ABR recordings in the absence of BACE1 strongly argue for a peripheral origin of the hearing loss.

Compared with wild-type littermates, BACE1 ${ }^{-1-}$ mice displayed significantly increased ABR thresholds in response to pure tones over a wide range of frequencies (e.g., $\sim+40 \mathrm{~dB}$ at $8 \mathrm{kHz}$ in ABR recordings (Fig. $1 A$ ), and also after broad-band click stimulation (Fig. $1 F$ ). We link this finding to a sensorineural hearing loss, because amplitudes of all ABR waves, especially of wave I, were significantly decreased, and DPOAE thresholds were elevated in BACE1-null mice. This pattern of electrophysiological abnormalities is an unequivocal sign of diminished sound sensitivity in the cochlea. At present, we do not know the reasons for the observed reduction in DPOAE amplitude. Given the normal $\mathrm{OHC}$ morphology and ex vivo physiology one might speculate about a potential gain of efferent inhibition of OHCs in $\mathrm{BACE} 1^{-/-}$mice, testing of which will require future studies. 
A

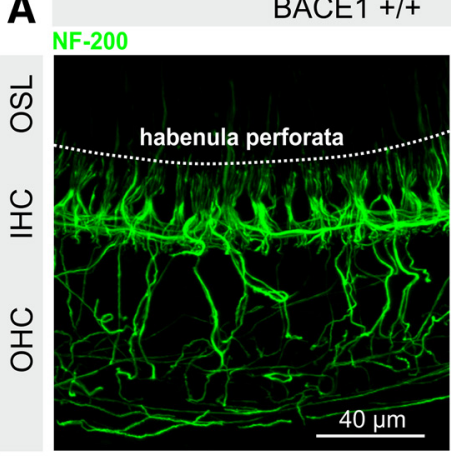

C

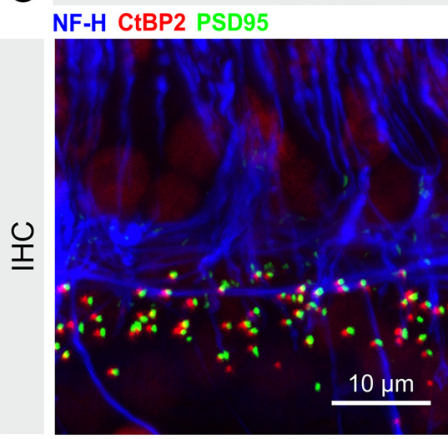

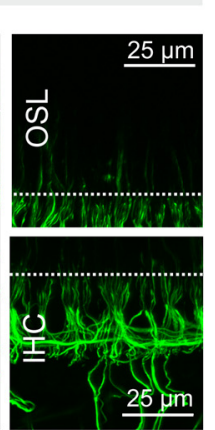
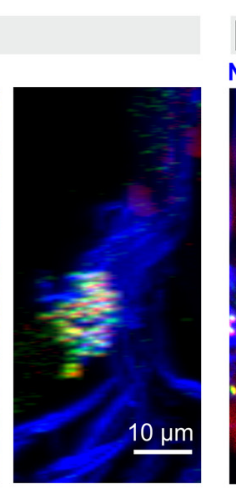

E

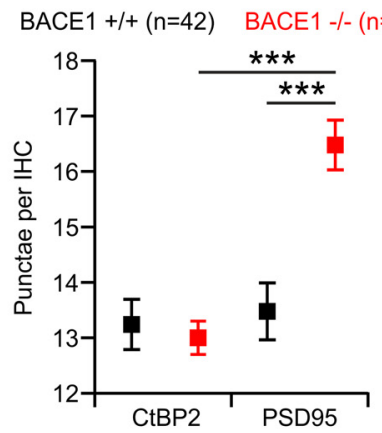

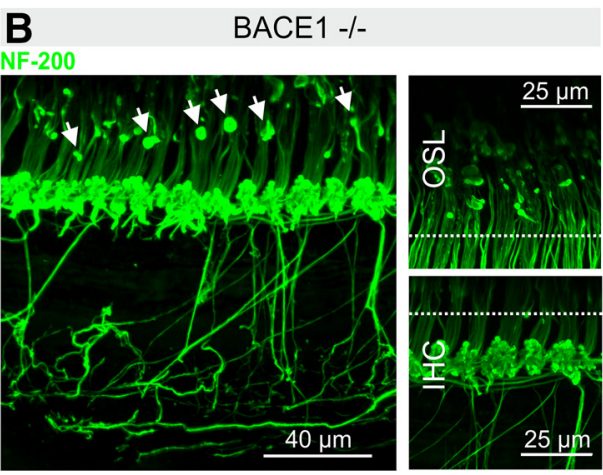

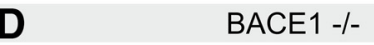

\section{NF-H CtBP2 PSD95}

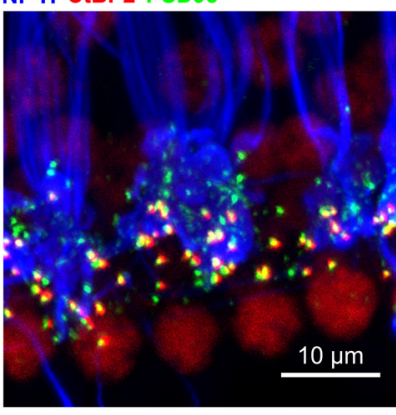

F
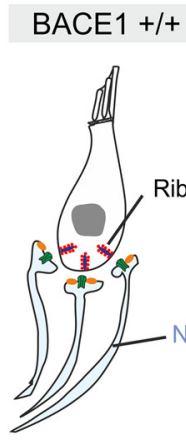

BACE1 -/-
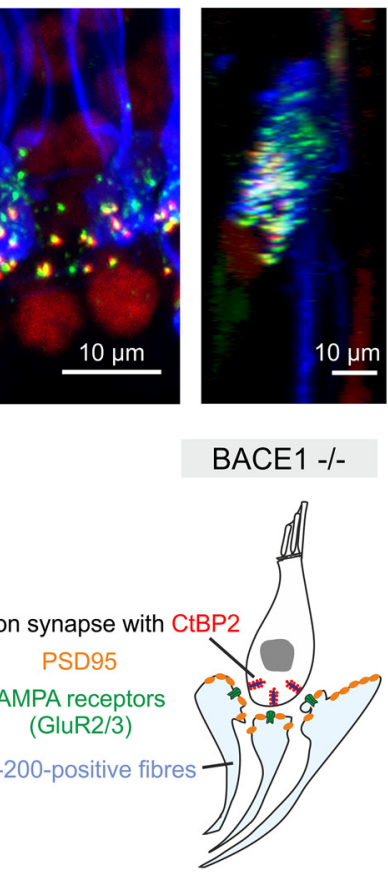

Figure 6. Disorganization of nerve fibers and ectopic overexpression of PSD95 in BACE1 ${ }^{-1-}$ mice. Auditory nerve fibers and the synaptic arrangement were analyzed in whole-mount organ of Corti preparations of the apical cochlear turn stained with primary antibodies targeted against neurofilament (NF-200 or NF-H, both are directed against neurofilament heavy chain polypeptide) and CtBP2 or PSD95, respectively. $\boldsymbol{A}, \boldsymbol{B}$, Auditory nerve fibers in the osseus spiral lamina (OSL) of BACE ${ }^{-1-}$ mice (in $\boldsymbol{B}$; P48) showed more intense anti-NF-200 immunofluorescence, and appeared disorganized and swollen. In the OSL of BACE1 ${ }^{-1-}$ mice, we detected NF-200-positive patches with very high immunofluorescence (arrowheads in $\boldsymbol{B}$ ) that were completely absent in wild-types. Dashed lines in $\boldsymbol{A}$ and $\boldsymbol{B}$ indicate the habenula perforata. Smaller images in $\boldsymbol{A}$ and $\boldsymbol{B}$ display magnifications of the OSL (top) and the IHC (bottom) region. $\boldsymbol{C}, \boldsymbol{D}$, Triple staining with antibodies directed against neurofilament (NF-H; blue), CtBP2 (presynaptic ribbon; red) and anti-PSD95 (postsynaptic density; green) showed that (C) in BACE1 $+/+$ mice the presynaptic and postsynaptic terminals were well aligned in close proximity. $D$, In BACE1 ${ }^{-1-}$ mice a substantial number of PSD95-positive clusters was located far outside the synaptic region and not aligned at all with presynaptic anti-CtBP2 signals. Maximum intensity projections of confocal $z$-stacks shown in the acquisition plane ( $x-y$, left) and in the orthogonal plane ( $z-y$, right). $\boldsymbol{E}$, Blinded counting of CtBP2- and PSD95-positive signals revealed significantly more PSD95 clusters in BACE1 ${ }^{-1-}$ than in BACE1 ${ }^{+/+}$mice $(p<0.001)$. In BACE1 ${ }^{-1-}$ mice, postsynaptic PSD95 clusters significantly outnumbered presynaptic CtBP2 clusters $(p<0.001)$. $\boldsymbol{F}$, Schematic drawing summarizing our findings (neurofilament-positive fibers, blue; PSD95, orange; $C$ tBP2, red; GluR2/3, green). ( $A-D)$ All images are representative confocal projections of the apical turn of the organ of Corti. Corresponding images $(\boldsymbol{A}, \boldsymbol{B}$ and $\boldsymbol{C}, \boldsymbol{D})$ were taken in parallel under identical experimental conditions (See Materials and Methods). ${ }^{* * *} p<0.001$.

Regardless of the precise mechanism, a reduction of cochlear amplification likely contributes to the hearing impairment of BACE $1^{-/-}$mice.

It might appear surprising that, despite the many in-depth studies of BACE1-deficient mice at all levels of examination, the hearing loss escaped the attention so far. However, since the mice are not completely deaf, their hearing phenotype is not plainly obvious, but requires detailed audiometric analysis. In view of our findings, previous studies reporting deficits of BACE $1^{-1-}$ mice in behavioral paradigms that used acoustic stimuli such as prepulse inhibition (Savonenko et al., 2008) and acoustic startle responses (Weber et al., 2017) should be discussed also in consideration of the hearing dysfunction of the mice described here.

BACE1 is essential for normal myelination of nerve fibers, axonal targeting and synapse formation in the cochlea As morphological substrates of the hearing loss, we identified hypomyelination of auditory nerve fibers, as well as disorganization and enlargement of postsynaptic terminals close to the IHC synaptic region. Compared with the auditory impairment in other mouse models of peripheral myelination defects (Zhou et al., 1995; Wan and Corfas, 2017), BACE1 knock-out mice exhibit a more pronounced elevation of $\mathrm{ABR}$ thresholds suggesting that 
A

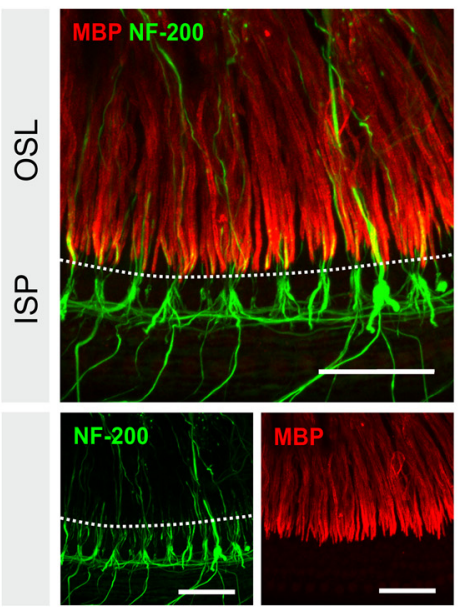

D
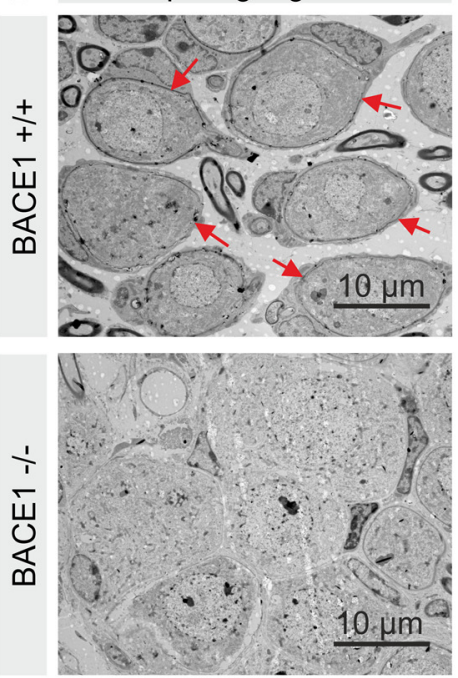

B

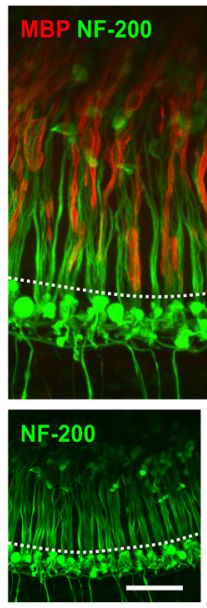

BACE1 -/-

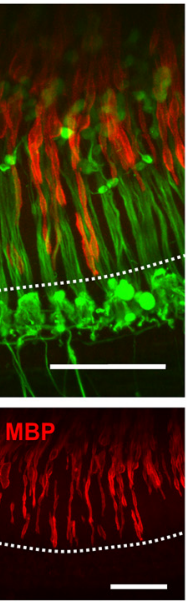

C

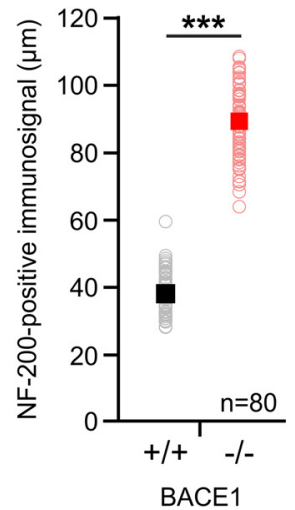

\section{E}
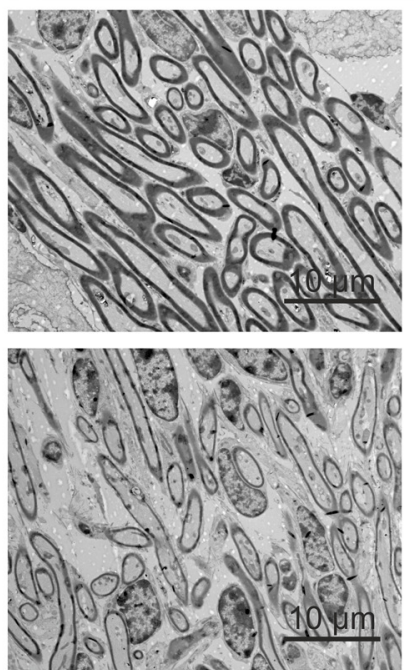

nerve fibers in OSL
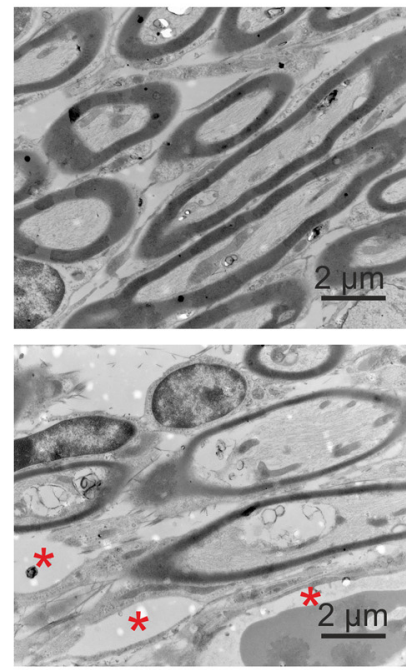

Figure 7. Deletion of BACE1 causes significant hypomyelination of auditory nerve fibers. $A, B$, Myelination of nerve fibers was largely reduced and fewer fibers showed myelination in $B A C E 1{ }^{-/-}$ mice, as demonstrated by substantially reduced anti-MBP immunosignals in the apical turn of the organ of Corti. Whole-mount organ of Corti preparations of adult $(\boldsymbol{A})$ BACE1 ${ }^{+/+}$and $(\boldsymbol{B})$ BACE1 ${ }^{-/-}$mice were stained with antibodies directed against MBP (red) and NF-200 (green). Note that in wild types, but not in BACE1 ${ }^{-1-}$ mice, anti-MBP immunosignals extended completely toward the habenula perforata (indicated by the dashed line). The panels show representative confocal projections; all scale bars represent $40 \mu \mathrm{m}$. $\boldsymbol{C}$, As measure for the traveling distance of fibers without myelination, we quantified the distance of NF-200-positive immunostaining from the inner spiral plexus (ISP) close to IHCs toward the osseous spiral lamina. 80 nerve fibers of 4 animals per genotype were analyzed blinded to the analyst with ImageJ (*** $\leq 0.001$; two-tailed two-sample $t$ test). Note that NF-200 preferentially recognizes non-myelinated segments of nerve fibers. $\boldsymbol{D}$, $\boldsymbol{E}$, TEM analysis in ultrathin sections of the cochlea (basal turns; $90 \mathrm{~nm}$ ) of $(\boldsymbol{D})$ the cell bodies of SGN neurons in the ganglion and $(\boldsymbol{E})$ of nerve fibers in the 0SL of adult wild-type (top) and BACE1 ${ }^{-1-}$ mice (bottom). D, Cell bodies of SGN in the ganglion of wild-type mice were covered with myelin sheaths (c.f. red arrows) that were almost completely absent in BACE1 ${ }^{-I-}$ mice. $E$, In knock-out mice, myelin sheaths of nerve fibers in the OSL were thinner in general and some fibers were not myelinated ( ${ }^{*}$ fibers in the $0 \mathrm{SL}$ ).

the synaptic abnormalities in their cochleae bear also functional relevance. In support of this notion, we found ectopically expressed PSD95 in these enlarged nodular structures. As the majority of myelinated fibers in the cochlea constitute type I fibers, loss of BACE1 affected the integrity of afferent SGN fibers carrying the auditory information from inner hair cells to brainstem nuclei as well as their postsynaptic compartments.

Disorganization of synaptic contact sites due to aberrant axonal targeting and hypomyelination of nerve fibers are not without precedent in BACE1-deficient mice (see Introduction and Results). In fact, NRG1 emerged as an important substrate of BACE1. NRG1 has multiple functions in myelination of peripheral axons and the induction of the muscle spindle, and depends on BACE1 cleavage to exert these roles (Michailov et al., 2004; Cheret et al., 2013). It was therefore plausible that in the auditory periphery, as in other areas of the nervous system, the abrogated processing of NRG1 by BACE1 causes changes like hypomyelination. Heterozygous Nrg1 knock-out mice display indeed an attenuated phenotype, i.e., hypomyelination and enlarged postsynaptic compartments (Fig. 10A). The fact that heterozygous loss of Nrg1 produced a weaker auditory phenotype than complete disruption of Bace1 might be attributable to higher levels of processed NRG1 in the former mice. Alternatively, there could be contribution of additional BACE1 substrates to normal cochlear function.

The extended FABP-positive area in $\mathrm{NRG} 1^{+/-}$and BACE1 ${ }^{-/-}$ mice illustrates the enlarged synaptic compartment, and the abnormally thin and retracted myelin sheath. Interestingly, NRG1 overexpressing mice exhibit decreased PSD95 gene expression in SGN fibers (Jin et al., 2011), and terminal Schwann cell-mediated 
A

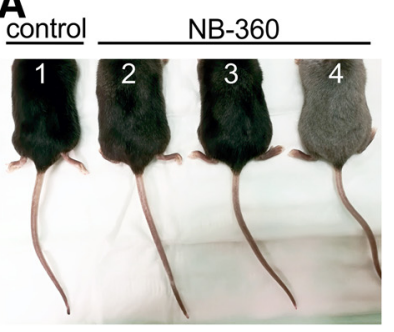

D
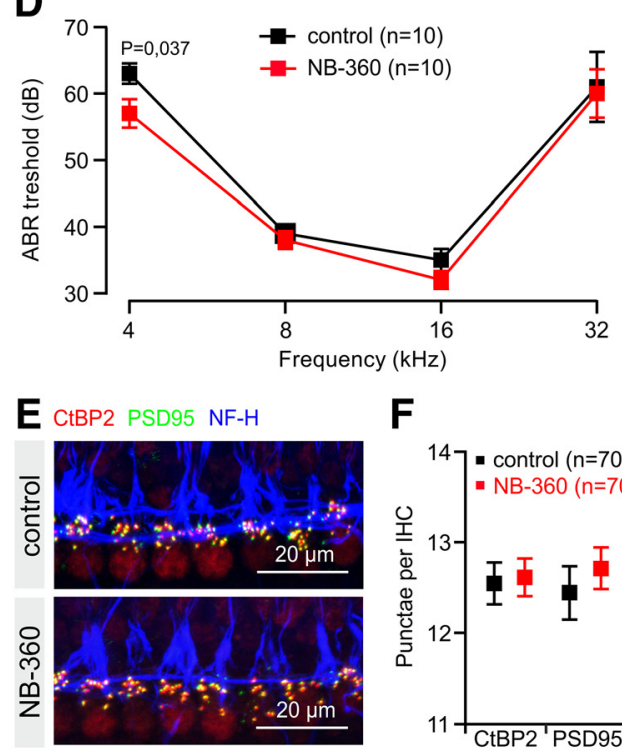

B
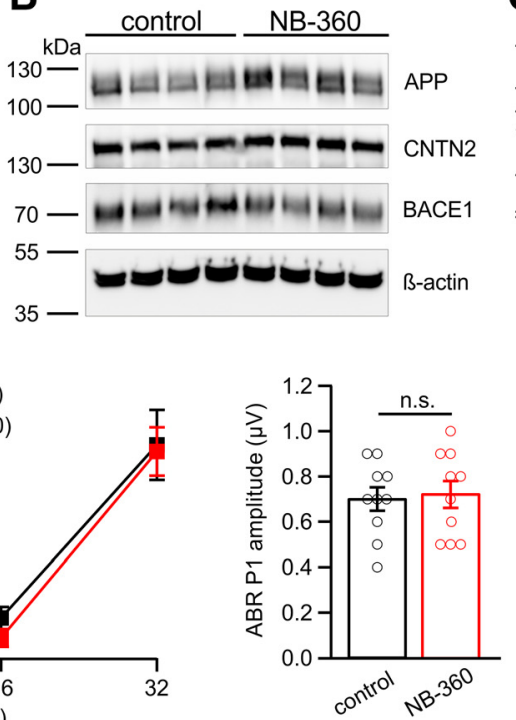

$\mathbf{F}$

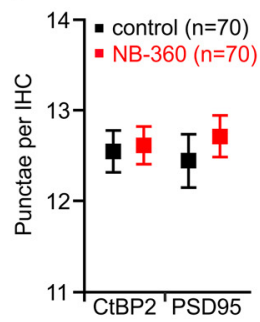

G

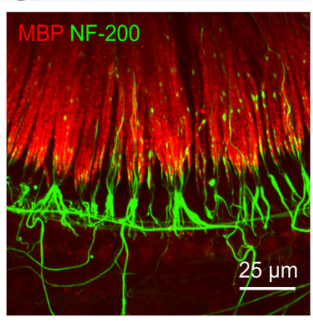

C
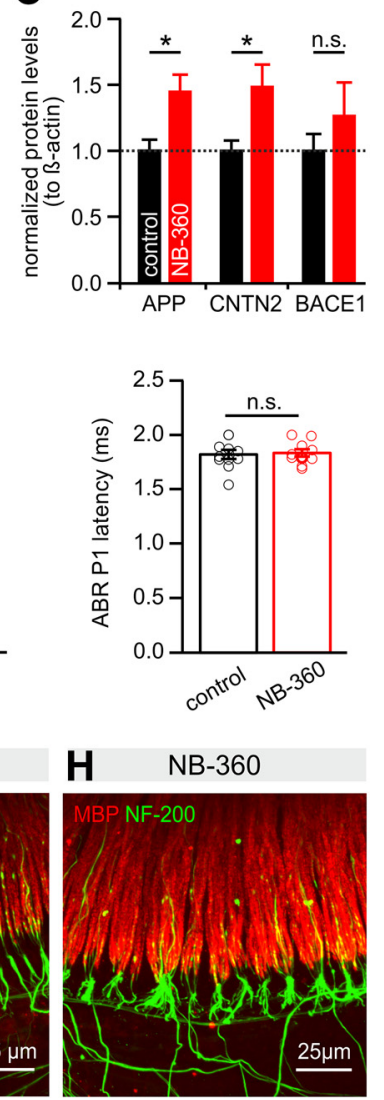

Figure 8. Treatment of mice with BACE inhibitor NB-360 does not cause hearing loss. $A$, Treatment of mice with NB-360 for 6 weeks led to significant changes of fur color ranging from the appearance of patches of gray hair (mouse 2, 3 versus control mouse 1) to general decolorization (mouse 4). $B, C$, Inhibition of BACE1 was evaluated by quantifying levels of APP, CNTN2 and BACE1 in brain lysates of four control and four NB-360-treated mice with Western blots. $\boldsymbol{C}$, Levels of these proteins were densitometrically quantified in Western blots as shown in $\boldsymbol{B}$, normalized to an internal standard to equalize between membranes, and normalized to the corresponding $\beta$-actin levels. Levels of untreated controls (black columns) were set to 1 for illustration. Red columns depict results for the BACE1 substrates CNTN2 and APP, as well as for BACE1 protein of NB-360-treated animals. The APP antibody is directed against the C terminus of APP (Bhattacharyya et al., 2013). The CNTN2 antibody is directed against GPI anchored full-length contactin-2 (Gautam et al., 2014) ( $n=6$ for controls and $n=8$ for NB-360-fed mice, ${ }^{*} p<0.05$, n.s., not significant, two-tailed two-sample $t$ test. $D$, Feeding of mice with NB-360 for 6 weeks did not induce hearing loss, as ABR thresholds, ABR wave I amplitude and latency were indistinguishable between control (black) and NB-360-treated (red) mice. The panel shows summary of ABR thresholds in response to pure tones, and the quantification of wave I (P1) amplitude (16 kHz at $90 \mathrm{~dB}$ ) and latency (16 kHz; $20 \mathrm{~dB}$ over threshold) ( $n=10$ for both groups). $E$, $\boldsymbol{F}$, Blinded counting of presynaptic CtBP2-(red) and postsynaptic PSD95-clusters (green) revealed no difference in synapse number and structure between control mice and mice fed with NB-360 (70 IHCs of 4 different animals per treatment group were analyzed; no significant difference). Organization and integrity of auditory nerve fibers, as visualized with antibodies directed against neurofilament (NF-H-immunosignals, blue), was also the same in both groups. $\boldsymbol{G}, \boldsymbol{H}$, As demonstrated by anti-MBP immunosignals (red), myelination of nerve fibers was indistinguishable between control mice and mice fed with NB-360. Also, anti-NF-200 signals were the same in both treatment groups and we did not detect any patches with high NF-200 immunofluorescence in the osseous spiral lamina (OSL) of mice fed with NB-360.E, G, and $\boldsymbol{H}$ show representative confocal projections of whole-mount explant cultures (apical cochlear turns) stained with primary antibodies against the indicated proteins.

synapse elimination of neuromuscular junctions depends on NRG1 (Lee et al., 2016). We therefore suggest that the converse phenotype, the increased number of PSD95-positive clusters around IHC synapses observed BACE1 null mice, is due to a lack of processed NRG1.

Analysis of the BACE1 ${ }^{-/-}$mice demonstrated a pronounced delay of the onset of peripheral myelination in OSL fibers by $\sim 10 \mathrm{~d}$. In the cochlea of adult BACE1-deficient mice, myelination was still incomplete, demonstrating that the developmental deficit cannot be compensated over time. Together with the observation that the inhibition of BACE1 in adult mice did not impair cochlear function and morphology, these data suggest that the auditory phenotype of $\mathrm{BACE} 1^{-/-}$mice represents predominantly a developmental disorder.

\section{BACE1 is unlikely to interact with $\mathrm{K}_{\mathrm{V}} 7$ channels in} the cochlea

Two types of KCNQ $\left(\mathrm{K}_{\mathrm{V}} 7\right)$ channels, KCNQ1/KCNE1 and KCNQ4, are essential for cochlear function. Mutations in either channel gene produce hearing deficits of varying degrees up to deafness (for review, see Jentsch, 2000; Maljevic et al., 2010). While KCNQ1/KCNE1 channel complexes located in marginal cells of the stria vascularis serve to maintain the high $\mathrm{K}^{+}$concentration of the endolymph, the prerequisite of the endochochlear potential, KCNQ4 provides the major $\mathrm{K}^{+}$conductance of OHCs (Kharkovets et al., 2006). As we have reported previously BACE1 interacts with KCNQ channels including the subtypes present in the cochlea in a complex fashion, involving both enzymatic and nonenzymatic effects (Sachse et al., 2013; Agsten et al., 2015; Hessler et al., 2015; Lehnert et al., 2016). Thus, we wondered whether changes in KCNQ channel expression or function might contribute to the hearing deficit of BACE1 ${ }^{-/-}$mice. Our evidence against an appreciable role of these channels is the following. First, in whole-cell voltage-clamp recordings of $\mathrm{K}^{+}$currents from OHCs of wild-type and mutant mice, we did not detect any significant difference, consistent with the lacking BACE1 staining of hair cells in immunohistochemical preparations of wild-type mice. Further support for the absence of 
A
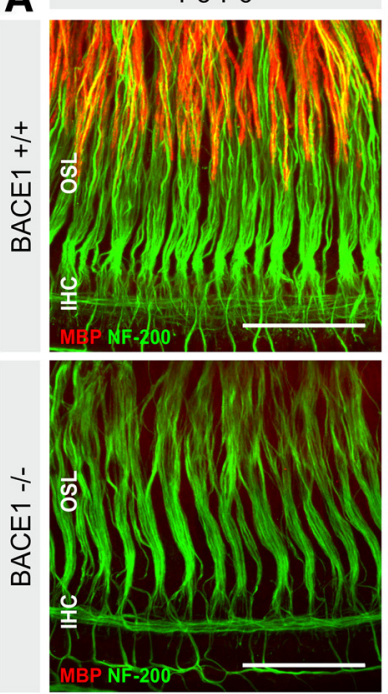

P8
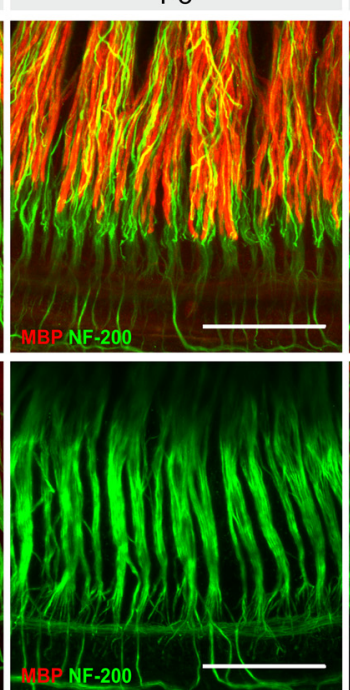

P14-P15
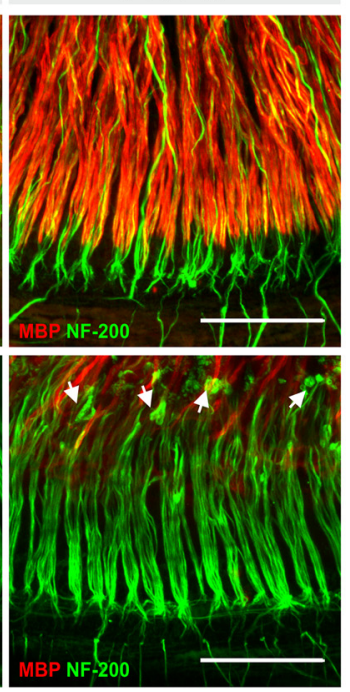
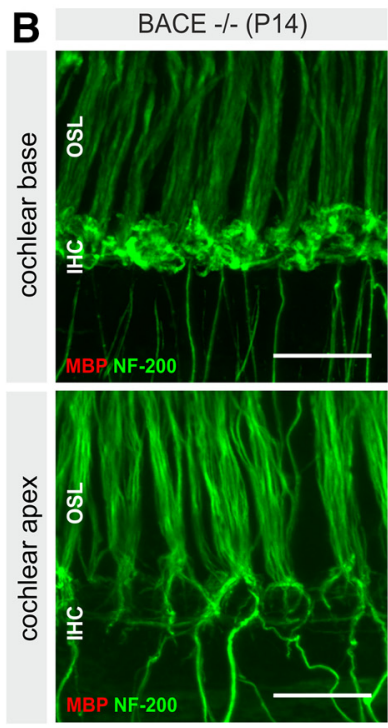

Figure 9. Postnatal myelination of SGN fibers is delayed in BACE1 ${ }^{-1-}$ mice. $A$, Compared with age-matched wild-type animals (top), onset of SGN fiber myelination was substantially delayed in BACE1 knock-out mice (bottom), and myelination was highly incomplete at P14-P15. Two weeks after birth, nodule patches with high NF-200 immunofluorescence appeared in the 0SL of BACE1 ${ }^{-1-}$ mice (white arrows). Note that NF-200 preferentially recognizes unmyelinated segments of nerve fibers. The panels show representative confocal $z$-stack projections of whole-mount preparations of the apical turn of the organ of Corti at indicated age; scale bars, $50 \mu \mathrm{m}$. Three animals were analyzed per age group. $\boldsymbol{B}$, Two weeks after birth, SGN fiber terminals were disorganized at the cochlear base, whereas fiber architecture in the cochlear apex was normal. At least three animals were analyzed per age group. In $\boldsymbol{A}$ and $\boldsymbol{B}$, myelination was visualized in whole-mount preparations of the apical turn of the organ of Corti using antibodies directed against MBP (red), SGN fibers were visualized with NF-200 (green). The postnatal day is indicated above the images. Scale bars, $20 \mu \mathrm{m}$.

A

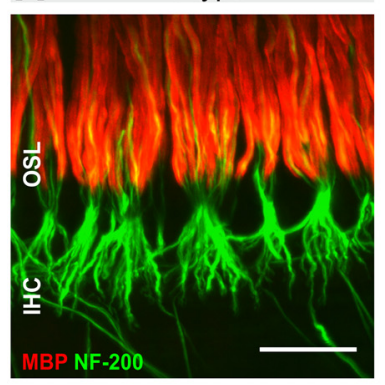

B

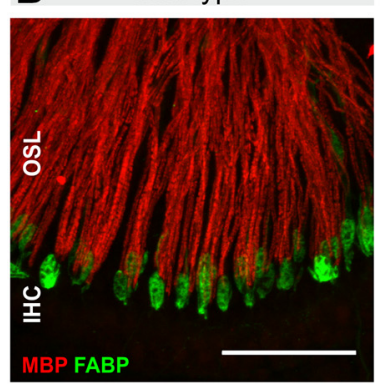

BACE1 -/-

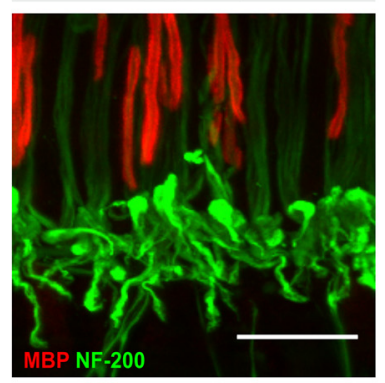

BACE1 -/-

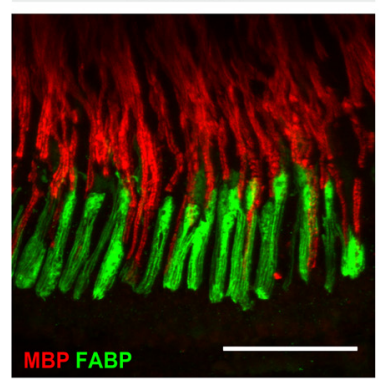

$\operatorname{Nrg} 1-\beta$

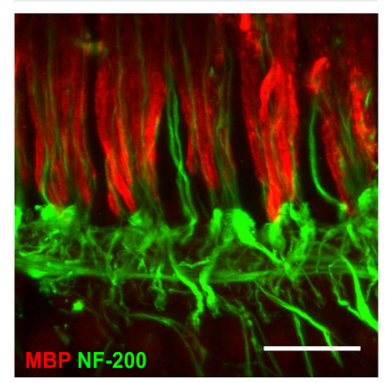

Nrg1- $\beta$

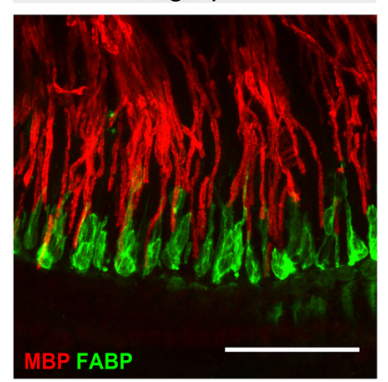

Figure 10. $\mathrm{NRG} 1^{-1+}$ mice display reduced myelination and abnormal fiber configuration. $\boldsymbol{A}$, Heterozygous $\mathrm{NRG1} 1^{-1+}$ mice (Nrg1- $\beta$, right) display hypomyelination, disorganization and abnormal enlargement of the synaptic region of SGN fibers in the cochlea 4 weeks after birth. Compared with BACE1 ${ }^{-1-}$ mice (middle), the reported abnormalities are similar albeit less pronounced. Scale bars represent $20 \mu \mathrm{m}$. $\boldsymbol{B}$, Visualization of nonmyelinated glia cells in the synaptic region of the cochlea with antibodies directed against FABP (brain-type fatty acid binding protein, green) in wild-type (left), BACE1 ${ }^{-1-}$ (middle), and NRG1 ${ }^{-/+}$mice (Nrg1- $\beta$; right). In both BACE1 ${ }^{-/-}$and NRG1 ${ }^{-/+}$mice, the nonmyelinated synaptic region was extended compared with wild-type mice. Scale bars represent $50 \mu \mathrm{m}$. $\boldsymbol{A}$ and $\boldsymbol{B}$ show representative maximum intensity projections of confocal $z$-stacks of the apical turn of the cochlea stained with the indicated antibodies. Four animals were examined per genotype.

BACE1 from hair cells comes from expression analyses made available through the SHIELD database (Shen et al., 2015). Second, immunostaining of marginal cells of the stria vascularis did not reveal expression of BACE1 in wild-type mice (Fig. 9A), and expression of KCNQ1 in these cells appeared unchanged in BACE1 knock-out mice (Fig. 2F). Finally, rodents with impaired peripheral myelination uniformly display elevated $\mathrm{ABR}$ thresholds, reduced ABR amplitudes and prolonged ABR latencies (for review, see Long et al., 2018). Thus, the auditory phenotype of BACE1 null mice can be fully explained based on the neuropathological aberrations in their cochleae, without considering a decrease in KCNQ currents.

We therefore conclude that, whereas BACE1 has considerable impact on KCNQ channel function in other regions of the nervous system and elsewhere in the body, such an interaction is unlikely to occur in marginal and hair cells of the cochlea, probably owing to the lack of sufficient expression of BACE1 in cells with significant KCNQ currents.

\section{Would BACE1 inhibitors worsen hearing function in $\mathrm{AD}$ ?}

A recent study on auditory function in a mouse model of $\mathrm{AD}$ reported reduced 
acoustic startle response and peripheral hearing loss (O'Leary et al., 2017). These AD mice showed increased ABR thresholds at 13-14 months of age and a significant higher loss of IHCs and $\mathrm{OHCs}$ in the cochlea at 15-16 months of age compared with age-matched wild-type mice (O'Leary et al., 2017). In a similar vein, clinical studies found a positive correlation between hearing loss and dementia, particularly in AD patients (Lin et al., 2013; Fritze et al., 2016).

The interdependence between cognitive decline and progressive hearing impairment, together with our data on an essential role of BACE1 for hearing, raises concerns regarding the envisaged chronic administration of BACE1 inhibitors to prevent and treat $\mathrm{AD}$. Such reservations appear the more justified as evidence is growing that the influence of BACE1 on synaptic morphology and function as well as on axon guidance is not restricted to development, but continues into adulthood, at least in brain regions rich in BACE1. For example, Bace1 gene deletion in the adult mouse brain leads to axon guidance defects and disorganization of the mossy fiber tract in the hippocampus (Ou-Yang et al., 2018). Moreover, in a pre-clinical study with 3 - 4 months old mice, a three-week administration of the orally available and blood-brain barrier permeable BACE1 inhibitor NB-360 reduced spine density of hippocampal pyramidal neurons and impaired synaptic long-term potentiation (Zhu et al., 2018). Similarly, inhibition of BACE1 in adulthood impairs muscle spindle morphology and function (Cheret et al., 2013). Thus, BACE1 functions are not restricted to development, but rather BACE1 is needed in adulthood.

To extrapolate possible side effects of chronic pharmacological BACE1 inhibition in the auditory system of patients, we treated wild-type animals with NB-360 at a dosage and over a time period ( 6 weeks) that proved sufficient to repair AD pathophysiology in a mouse model (Keskin et al., 2017). Although BACE1 is highly expressed in SGNs and olivocochlear efferent terminals in the cochlea, we did not detect hearing deficits or neuropathological abnormalities in the treated group. Therefore, systemic delivery of this BACE1-inhibitor in adulthood does not compromise hearing. Nevertheless, some caveats must be expressed when translating this finding to the clinical setting. One important issue that remains to be addressed relates to the function of the high levels of BACE1 expression in parts of the mature cochlea. It seems conceivable that BACE1 is important for the long-term maintenance or regeneration of axonal myelination and of proper synaptic function in the cochlea and might be in particular demand in the elderly to slow age-dependent hearing decline. We cannot rule out that such favorable properties of BACE1 might have remained undetected with our treatment protocol or will become only apparent in the inner ear of humans. While the oral route of NB-360 application proved effective in our hands to inhibit BACE1 activity in the mouse brain, indicating good blood-brain barrier permeability, it remains to be determined whether the drug is equally well permeable across the blood-labyrinth barrier, and if so, whether the pharmacokinetic profile is comparable to that in the human cochlea. Until these questions are resolved, clinical trials with BACE1 inhibitors would be well advised to consider regular hearing tests.

\section{References}

Agsten M, Hessler S, Lehnert S, Volk T, Rittger A, Hartmann S, Raab C, Kim DY, Groemer TW, Schwake M, Alzheimer C, Huth T (2015) BACE1 modulates gating of KCNQ1 (Kv7.1) and cardiac delayed rectifier KCNQ1/KCNE1 (IKs). J Mol Cell Cardiol 89:335-348.

Bhattacharyya R, Barren C, Kovacs DM (2013) Palmitoylation of amyloid precursor protein regulates amyloidogenic processing in lipid rafts. J Neurosci 33:11169-11183.

Cheret C, Willem M, Fricker FR, Wende H, Wulf-Goldenberg A, Tahirovic S, Nave KA, Saftig P, Haass C, Garratt AN, Bennett DL, Birchmeier C (2013) Bacel and neuregulin-1 cooperate to control formation and maintenance of muscle spindles. EMBO J 32:2015-2028.

Cole SL, Vassar R (2007) The basic biology of BACE1: a key therapeutic target for Alzheimer's disease. Curr Genomics 8:509-530.

Dominguez D, Tournoy J, Hartmann D, Huth T, Cryns K, Deforce S, Serneels L, Camacho IE, Marjaux E, Craessaerts K, Roebroek AJ, Schwake M, D’Hooge R, Bach P, Kalinke U, Moechars D, Alzheimer C, Reiss K, Saftig P, De Strooper B (2005) Phenotypic and biochemical analyses of BACE1- and BACE2-deficient mice. J Biol Chem 280:30797-30806.

Fritze T, Teipel S, Óvári A, Kilimann I, Witt G, Doblhammer G (2016) Hearing impairment affects dementia incidence. an analysis based on longitudinal health claims data in germany. PLoS One 11:e0156876.

Gale JE, Marcotti W, Kennedy HJ, Kros CJ, Richardson GP (2001) FM1-43 dye behaves as a permeant blocker of the hair-cell mechanotransducer channel. J Neurosci 21:7013-7025.

Gautam V, D’Avanzo C, Hebisch M, Kovacs DM, Kim DY (2014) BACE1 activity regulates cell surface contactin-2 levels. Mol Neurodegener 9:4.

Hansen MR, Vijapurkar U, Koland JG, Green SH (2001) Reciprocal signaling between spiral ganglion neurons and schwann cells involves neuregulin and neurotrophins. Hear Res 161:87-98.

Hartmann S, Zheng F, Kyncl MC, Karch S, Voelkl K, Zott B, D’Avanzo C, Lomoio S, Tesco G, Kim DY, Alzheimer C, Huth T (2018) $\beta$-secretase BACE1 promotes surface expression and function of Kv3.4 at hippocampal mossy fiber synapses. J Neurosci 38:3480-3494.

Hessler S, Zheng F, Hartmann S, Rittger A, Lehnert S, Völkel M, Nissen M, Edelmann E, Saftig P, Schwake M, Huth T, Alzheimer C (2015) $\beta$-secretase BACE1 regulates hippocampal and reconstituted M-currents in a $\beta$-subunit-like fashion. J Neurosci 35:3298-3311.

Huang G, Santos-Sacchi J (1993) Mapping the distribution of the outer hair cell motility voltage sensor by electrical amputation. Biophys J 65:2228 2236.

Hu X, Hicks CW, He W, Wong P, Macklin WB, Trapp BD, Yan R (2006) Bacel modulates myelination in the central and peripheral nervous system. Nat Neurosci 9:1520-1525.

Hu X, Fan Q, Hou H, Yan R (2016) Neurological dysfunctions associated with altered BACE1-dependent neuregulin-1 signaling. J Neurochem 136:234-249.

Jentsch TJ (2000) Neuronal KCNQ potassium channels: physiology and role in disease. Nat Rev Neurosci 1:21-30.

Jin D, Ohlemiller KK, Lei D, Dong E, Role L, Ryugo DK, Bao J (2011) Agerelated neuronal loss in the cochlea is not delayed by synaptic modulation. Neurobiol Aging 32:2321.e13-e23.

Johnson SL, Beurg M, Marcotti W, Fettiplace R (2011) Prestin-driven cochlear amplification is not limited by the outer hair cell membrane time constant. Neuron 70:1143-1154.

Kandalepas PC, Vassar R (2014) The normal and pathologic roles of the Alzheimer's $\beta$-secretase, BACE1. Curr Alzheimer Res 11:441-449.

Kane KL, Longo-Guess CM, Gagnon LH, Ding D, Salvi RJ, Johnson KR (2012) Genetic background effects on age-related hearing loss associated with Cdh23 variants in mice. Hear Res 283:80-88.

Keskin AD, Kekuš M, Adelsberger H, Neumann U, Shimshek DR, Song B, Zott B, Peng T, Förstl H, Staufenbiel M, Nelken I, Sakmann B, Konnerth A, Busche MA (2017) BACE inhibition-dependent repair of Alzheimer's pathophysiology. Proc Natl Acad Sci U S A 114:8631-8636.

Kharkovets T, Dedek K, Maier H, Schweizer M, Khimich D, Nouvian R, Vardanyan V, Leuwer R, Moser T, Jentsch TJ (2006) Mice with altered KCNQ4 K+ channels implicate sensory outer hair cells in human progressive deafness. EMBO J 25:642-652.

Khimich D, Nouvian R, Pujol R, Tom Dieck S, Egner A, Gundelfinger ED, Moser T (2005) Hair cell synaptic ribbons are essential for synchronous auditory signalling. Nature 434:889-894.

Kuhn PH, Koroniak K, Hogl S, Colombo A, Zeitschel U, Willem M, Volbracht C, Schepers U, Imhof A, Hoffmeister A, Haass C, Ro $\beta$ ner S, Bräse S, Lichtenthaler SF (2012) Secretome protein enrichment identifies physiological BACE1 protease substrates in neurons. EMBO J 31:3157-3168.

Kujawa SG, Liberman MC (2009) Adding insult to injury: cochlear nerve degeneration after "temporary" noise-induced hearing loss. J Neurosci 29:14077-14085 
Kurtz A, Zimmer A, Schnütgen F, Brüning G, Spener F, Müller T (1994) The expression pattern of a novel gene encoding brain-fatty acid binding protein correlates with neuronal and glial cell development. Development 120:2637-2649.

Lee YI, Li Y, Mikesh M, Smith I, Nave KA, Schwab MH, Thompson WJ (2016) Neuregulin1 displayed on motor axons regulates terminal schwann cell-mediated synapse elimination at developing neuromuscular junctions. Proc Natl Acad Sci U S A 113:E479-E487.

Lehnert S, Hartmann S, Hessler S, Adelsberger H, Huth T, Alzheimer C (2016) Ion channel regulation by $\beta$-secretase BACE1 - enzymatic and non-enzymatic effects beyond Alzheimer's disease. Channels 10:365-378.

Leitner MG, Halaszovich CR, Oliver D (2011) Aminoglycosides inhibit KCNQ4 channels in cochlear outer hair cells via depletion of phosphatidylinositol(4,5)bisphosphate. Mol Pharmacol 79:51-60.

Leitner MG, Feuer A, Ebers O, Schreiber DN, Halaszovich CR, Oliver D (2012) Restoration of ion channel function in deafness-causing KCNQ4 mutants by synthetic channel openers. Br J Pharmacol 165:2244-2259.

Li L (2003) Isoform-specific knock-out of the Neuregulin-1 gene. InauguralDissertation zur Erlangung des Doktorgrades der MathematischNaturwissenschaftlichen Fakultät der Universität zu Köln. Available at https://pdfs.semanticscholar.org/f9f6/625ce08de27edf1251a8c304a4823 clff175.pdf?_ga $=2.261360073 .592192026 .1572018637-1974222216.155265$ 2373.

Lin FR, Ph MDD, Yaffe K, Xia J, Xue QL, Ph D, Harris TB, Purchase-Helzner E, Satterfield S, Ayonayon HN, Ferrucci L, Simonsick EM (2013) Hearing loss and cognitive decline in older adults. JAMA Intern Med 173: 293-299.

Lin HW, Furman AC, Kujawa SG, Liberman MC (2011) Primary neural degeneration in the guinea pig cochlea after reversible noise-induced threshold shift. J Assoc Res Otolaryngol 12:605-616.

Long P, Wan G, Roberts MT, Corfas G (2018) Myelin development, plasticity, and pathology in the auditory system. Dev Neurobiol 78:80-92.

Maljevic S, Wuttke TV, Seebohm G, Lerche H (2010) KV7 channelopathies. Pflugers Arch 460:277-288.

Meyers JR, MacDonald RB, Duggan A, Lenzi D, Standaert DG, Corwin JT, Corey DP (2003) Lighting up the senses: FM1-43 loading of sensory cells through nonselective ion channels. J Neurosci 23:4054-4065.

Michailov GV, Sereda MW, Brinkmann BG, Fischer TM, Haug B, Birchmeier C, Role L, Lai C, Schwab MH, Nave KA (2004) Axonal neuregulin-1 regulates myelin sheath thickness. Science 304:700-703.

Morley BJ (1998) ARIA is heavily expressed in rat peripheral auditory and vestibular ganglia. Brain Res Mol Brain Res 54:170-174.

Nayagam BA, Muniak MA, Ryugo DK (2011) The spiral ganglion: connecting the peripheral and central auditory systems. Hear Res 278:2-20.

Neumann U, Rueeger H, Machauer R, Veenstra SJ, Lueoend RM, TintelnotBlomley M, Laue G, Beltz K, Vogg B, Schmid P, Frieauff W, Shimshek DR, Staufenbiel M, Jacobson LH (2015) A novel BACE inhibitor NB-360 shows a superior pharmacological profile and robust reduction of amyloid- $\beta$ and neuroinflammation in APP transgenic mice. Mol Neurodegener 10:44.

O'Leary TP, Shin S, Fertan E, Dingle RN, Almuklass A, Gunn RK, Yu Z, Wang J, Brown RE (2017) Reduced acoustic startle response and peripheral hearing loss in the 5xFAD mouse model of Alzheimer's disease. Genes Brain Behav 16:554-563.

Oliver D, Fakler B (1999) Expression density and functional characteristics of the outer hair cell motor protein are regulated during postnatal development in rat. J Physiol 519:791-800.

Oliver D, Knipper M, Derst C, Fakler B (2003) Resting potential and submembrane calcium concentration of inner hair cells in the isolated mouse cochlea are set by KCNQ-type potassium channels. J Neurosci 23:2141-2149.

Ou-Yang MH, Kurz JE, Nomura T, Popovic J, Rajapaksha TW, Dong H, Contractor A, Chetkovich DM, Tourtellotte WG, Vassar R (2018) Axonal organization defects in the hippocampus of adult conditional BACE1 knockout mice. Sci Transl Med 10:eaao5620.

Ray B, Roy TS, Wadhwa S, Roy KK (2005) Development of the human fetal cochlear nerve: a morphometric study. Hear Res 202:74-86.

Sachse CC, Kim YH, Agsten M, Huth T, Alzheimer C, Kovacs DM, Kim DY (2013) BACE1 and presenilin/ $\gamma$-secretase regulate proteolytic processing of KCNE1 and 2, auxiliary subunits of voltage-gated potassium channels. FASEB J 27:2458-2467.

Savonenko AV, Melnikova T, Laird FM, Stewart KA, Price DL, Wong PC
(2008) Alteration of BACE1-dependent NRG1/ErbB4 signaling and schizophrenia-like phenotypes in BACE1-null mice. Proc Natl Acad Sci U S A 105:5585-5590.

Schindelin J, Arganda-Carreras I, Frise E, Kaynig V, Longair M, Pietzsch T, Preibisch S, Rueden C, Saalfeld S, Schmid B, Tinevez JY, White DJ, Hartenstein V, Eliceiri K, Tomancak P, Cardona A (2012) Fiji: an opensource platform for biological-image analysis. Nat Methods 9:676-682.

Shen J, Scheffer DI, Kwan KY, Corey DP (2015) SHIELD: an integrative gene expression database for inner ear research. Database (Oxford) 2015:bav071.

Shimshek DR, Jacobson LH, Kolly C, Zamurovic N, Balavenkatraman KK, Morawiec L, Kreutzer R, Schelle J, Jucker M, Bertschi B, Theil D, Heier A, Bigot K, Beltz K, Machauer R, Brzak I, Perrot L, Neumann U (2016) Pharmacological BACE1 and BACE2 inhibition induces hair depigmentation by inhibiting PMEL17 processing in mice. Sci Rep 6:21917.

Stankovic K, Rio C, Xia A, Sugawara M, Adams JC, Liberman MC, Corfas G (2004) Survival of adult spiral ganglion neurons requires erbB receptor signaling in the inner ear. J Neurosci 24:8651-8661.

Taveggia C, Zanazzi G, Petrylak A, Yano H, Rosenbluth J, Einheber S, Xu X, Esper RM, Loeb JA, Shrager P, Chao MV, Falls DL, Role L, Salzer JL (2005) Neuregulin-1 type III determines the ensheathment fate of axons. Neuron 47:681-694.

Vassar R, Bennett BD, Babu-Khan S, Kahn S, Mendiaz EA, Denis P, Teplow DB, Ross S, Amarante P, Loeloff R, Luo Y, Fisher S, Fuller J, Edenson S, Lile J, Jarosinski MA, Biere AL, Curran E, Burgess T, Louis JC et al. (1999) Beta-secretase cleavage of Alzheimer's amyloid precursor protein by the transmembrane aspartic protease BACE. Science 286:735-741.

Velanac V, Unterbarnscheidt T, Hinrichs W, Gummert MN, Fischer TM, Rossner MJ, Trimarco A, Brivio V, Taveggia C, Willem M, Haass C, Möbius W, Nave KA, Schwab MH (2012) Bacel processing of NRG1 type III produces a myelin-inducing signal but is not essential for the stimulation of myelination. Glia 60:203-217.

Vogl C, Cooper BH, Neef J, Wojcik SM, Reim K, Reisinger E, Brose N, Rhee JS, Moser T, Wichmann C (2015) Unconventional molecular regulation of synaptic vesicle replenishment in cochlear inner hair cells. J Cell Sci 128:638-644

Vogl C, Butola T, Haag N, Hausrat TJ, Leitner MG, Moutschen M, Lefèbvre PP, Speckmann C, Garrett L, Becker L, Fuchs H, Hrabe de Angelis M, Nietzsche S, Kessels MM, Oliver D, Kneussel M, Kilimann MW, Strenzke $\mathrm{N}$ (2017) The BEACH protein LRBA is required for hair bundle maintenance in cochlear hair cells and for hearing. EMBO Rep 18:2015-2029.

Wan G, Corfas G (2017) Transient auditory nerve demyelination as a new mechanism for hidden hearing loss. Nat Commun 8:14487.

Weber M, Wu T, Meilandt WJ, Dominguez SL, Solanoy HO, Maloney JA, Ngu H, Baca M, Kung C, Lima L, Earr TK, Fleck D, Shields SD, Forrest WF, Foreman O, Warming S, Watts RJ, Scearce-Levie K (2017) BACE1 across species: a comparison of the in vivo consequences of BACE1 deletion in mice and rats. Sci Rep 7:44249.

Wilke BU, Lindner M, Greifenberg L, Albus A, Kronimus Y, Bünemann M, Leitner MG, Oliver D (2014) Diacylglycerol mediates regulation of TASK potassium channels by gq-coupled receptors. Nat Commun 5:5540.

Willem M, Garratt AN, Novak B, Citron M, Kaufmann S, Rittger A, DeStrooper B, Saftig P, Birchmeier C, Haass C (2006) Control of peripheral nerve myelination by the beta-secretase BACE1. Science 314:664-666.

Yan R, Bienkowski MJ, Shuck ME, Miao H, Tory MC, Pauley AM, Brashier JR, Stratman NC, Mathews WR, Buhl AE, Carter DB, Tomasselli AG, Parodi LA, Heinrikson RL, Gurney ME (1999) Membrane-anchored aspartyl protease with Alzheimer's disease beta-secretase activity. Nature 402:533-537.

Zhou L, Barão S, Laga M, Bockstael K, Borgers M, Gijsen H, Annaert W, Moechars D, Mercken M, Gevaert K, Gevaer K, De Strooper B (2012) The neural cell adhesion molecules L1 and CHL1 are cleaved by BACE1 protease in vivo. J Biol Chem 287:25927-25940.

Zhou R, Assouline JG, Abbas PJ, Messing A, Gantz BJ (1995) Anatomical and physiological measures of auditory system in mice with peripheral myelin deficiency. Hear Res 88:87-97.

Zhu K, Xiang X, Filser S, Marinković P, Dorostkar MM, Crux S, Neumann U, Shimshek DR, Rammes G, Haass C, Lichtenthaler SF, Gunnersen JM, Herms J (2018) Beta-site amyloid precursor protein cleaving enzyme 1 inhibition impairs synaptic plasticity via seizure protein 6. Biol Psychiatry $83: 428-437$. 